\title{
Influence of the chemical and electronic structure on the electrical behavior of zirconium oxynitride films
}

\author{
P. Carvalho, J. M. Chappé ${ }^{1}$, L. Cunha², S. Lanceros-Méndez², P. Alpuim¹ ${ }^{1}$ F. Vaz ${ }^{1}$, E. Alves ${ }^{3}$, C. \\ Rousselot ${ }^{1}$, J. P. Espinós ${ }^{5}$, and A. R. González-Elipe ${ }^{5}$ \\ ${ }^{1}$ Centro de Física, Universidade do Minho, 4800-058 Guimarães, Portugal \\ ${ }^{2}$ Centro de Física, Universidade do Minho, 4800-058 Guimarães, Portugal \\ ${ }^{3}$ Departamento de Física, Instituto Tecnológico Nuclear, E.N. 10, 2686-953 Sacavém, Portugal \\ ${ }^{4}$ Département MN2S, Institut FEMTO-ST (UMR CNRS 6174), University of Franche Comté, BP 71427, F-25211 \\ Montbéliard Cedex, France \\ ${ }^{5}$ Instituto de Ciencia de Materiales de Sevilla, CSIC-University of Sevilla, Avda. Américo Vespucio s/n, 41092 \\ Sevilla, Spain
}

This work is devoted to the investigation of decorative zirconium oxynitride, $\mathrm{ZrO}_{x} \mathrm{~N}_{y}$, films prepared by dc reactive magnetron sputtering, using a 17:3 nitrogen-to-oxygen-ratio gas mixture. The color of the films changed from metallic-like, very bright yellow pale, and golden yellow, for low gas mixture flows [from 0 to about 9 SCCM (SCCM denotes cubic centimeter per minute at

STP)] to red brownish for intermediate gas flows (values up to 12 SCCM). Associated to this color change there is a significant decrease of brightness. With further increase of the reactive gas flow, the color of the samples changed from red brownish to dark blue (samples prepared with 13 and 14 SCCM). The films deposited with gas flows above 14 SCCM showed only apparent colorations due to interference effects. This change in optical behavior from opaque to transparent (characteristic of a transition from metallic to insulating-type materials), promoted by the change in gas flow values, revealed that significant changes were occurring in the film structure and electronic properties, thus opening new potential applications for the films, beyond those of purely decorative ones. Taking this into account, the electrical behavior of the films was investigated as a function of the reactive gas flow and correlated with the observed chemical, electronic, and structural features. The variations in composition disclosed the existence of four different zones, which were correlated to different crystalline structures. For the so-called zone I, x-ray diffraction revealed the development of films with a $\mathrm{B} 1 \mathrm{NaCl}$ face-centered cubic zirconium nitride-type phase, with some texture changes. Increasing the reactive gas flow, the structure of the films is that of a poorly crystallized over-stoichiometric nitride phase, which may be similar to that of $Z_{3} \mathrm{~N}_{4}$, but with some probable oxygen inclusions within nitrogen positions. This region was characterized as zone II. Zone III was indexed as an oxynitride-type phase, similar to that of $\gamma-\mathrm{Zr}_{2} \mathrm{ON}_{2}$ with some oxygen atoms occupying some of the nitrogen positions. Finally, occurring at the highest flow rates, zone IV was assigned to a $\mathrm{ZrO}_{2}$ monoclinic-type structure. The composition/structure variations were consistent with the chemical bonding analysis carried out by x-ray photoelectron spectroscopy, which showed oxygen doping in both $\mathrm{Zr}_{3} \mathrm{~N}_{4}$ - and $\mathrm{ZrN}$-type grown films. The electronic properties of the films exhibited significant changes from zone to zone. Resistivity measurements revealed a very wide range of values, varying from relatively highly conductive materials (for zone I) with resistivity values around few hundreds of $\mu \Omega \mathrm{cm}$ to highly insulating films within zones III and IV, which presented resistivity values in the order of $1015 \mu \Omega \mathrm{cm}$. Regarding zone II, corresponding to oxygen doped $\mathrm{Zr}_{3} \mathrm{~N}_{4}$-type compounds, the observed behavior revealed resistivity values increasing steeply from about 103 up to $1015 \mu \Omega \mathrm{cm}$, indicating a systematic transition from metallic to insulating regimes.

\section{INTRODUCTION}

The increasing demand of modern industry for constant improvement of material properties especially designed for several types of devices, including those in electronic and optoelectronic, ${ }^{1,2}$ optical, ${ }^{3}$ mechanical, ${ }^{4}$ and tribological ${ }^{5}$ applications, among others, have prompted the development of a large number of technologies, optimized both in terms of the final in-service behavior and from the point of view of

\footnotetext{
author to whom correspondence should be addressed. Electronic mail: fvaz@ fisica.uminho.pt.
}

environmentally conscious manufacturing. ${ }^{6,7}$ In this particular point, the use of thin films deposited onto a variety of substrate materials (ranging from common glass or silicon for optical and electronic/optoelectronics applications, ${ }^{8,9}$ to steel and other metallic materials for mechanical/tribological devices/parts ${ }^{5,10}$ and, more recently, on to polymeric-based parts ${ }^{11,12}$ ) is attracting the attention of both research groups and industry. ${ }^{13,14}$ Physical vapour deposition (PVD) thin film technology has been applied with enormous success in several of these technological fields due to the wide range of material combinations and therefore the significant number 
of possible property gradients. ${ }^{15}$ Examples of success include the use of thin films in the development of several types of optical filters, ${ }^{16,17}$ solar cells/collectors, ${ }^{18}$ structural components, ${ }^{19}$ optical devices for UV-visible spectral region applications, ${ }^{17,20}$ colored layers, ${ }^{21}$ automotive parts, ${ }^{22,23}$ among other examples, providing unique benefits in terms of lifetime and performance.

In spite of these successes, modern research is turning gradually toward what one might call the multifunctional materials. By proper selection of coating method and material, it is possible to prepare thin films that may combine attractive properties including high thermal stability and electrical resistivity, low dielectric constant, high thermal conductivity, high acoustic wave conduction velocity, wide band gap, etc. These offer a promising approach for a variety of applications in electronic, optoelectronic, and other related fields. $^{24,25}$

In terms of specific examples of synthetic materials used in these above mentioned applications, the thin transition metal oxide films, $\mathrm{MeO}_{x}$, are frequently applied in several optical devices, ${ }^{26,27}$ such as antireflection and dense wavelength multiplexing devices and switchable windows. These applications are enabled by the excellent mechanical properties of oxide-based films together with a good chemical stability, high index of refraction, and wide optical band gap. On the other hand, transition metal mononitrides such as $\mathrm{ZrN}, \mathrm{TiN}$, and $\mathrm{HfN}$ are used as refractory compounds. They exhibit a wide number of exceptional physical properties, including their relatively high hardness, high melting point, chemical stability, and corrosion resistance. ${ }^{28}$ The exceptional physical properties of refractory materials can be understood by taking into account that the binding mechanism comprises three bonding types: metallic, covalent, and ionic. ${ }^{29,30}$ Zirconium nitride, $\mathrm{ZrN}$, has a melting point temperature of $3250 \mathrm{~K}$, a typical electrical resistivity of the order of few tenths of $\mu \Omega \mathrm{cm}$, a thermal conductivity also in the order of few tenths of $\mathrm{W} \mathrm{m} \mathrm{K}{ }^{-1}$, and a superconducting transition temperature of $9 \mathrm{~K},{ }^{31}$ which are closely related to its electronic structure. ${ }^{28,29,32,33}$ For a careful and systematic investigation of this combination of properties, experimental investigations using techniques such as photoelectron spectroscopy, which probes the electronic density of states (DOS), are of great interest. ${ }^{34}$ In fact, it is known that the nonvanishing DOS at the Fermi energy, $E_{F}$, is responsible for the metallic conductivity of $\mathrm{ZrN}$. Schwarz et al. ${ }^{35}$ reported that the particular electronic structure of $\mathrm{ZrN}$ consists of a low-lying $\mathrm{N} 2 s$ band followed by the $p$ band, which mainly originates from $\mathrm{N} 2 p$ states, but with significant contribution from $\mathrm{Zr} 4 d$ orbitals. The covalent interactions between $\mathrm{Zr} 4 d$ and $\mathrm{N} 2 p$ orbitals result in the high hardness and high melting point.

The next band is primarily derived from $\mathrm{Zr} 4 d$ states and, thus, is denoted as $d$ band, which, in the case of $\mathrm{ZrN}$, overlaps the $p$-band. Between the " $p$ band" and " $d$ band," there is a minimum in the DOS at eight valence electrons. From this minimum, the DOS steadily increases until all nine valence electrons of $\mathrm{ZrN}$ are accommodated, and so the Fermi energy $E_{F}$, lies in the $d$ band with a relatively high DOS. Due to these properties, $\mathrm{ZrN}$ is widely used in several technological domains, such as mechanical rotation tools, ${ }^{36}$ cryogenic thermometers, ${ }^{37}$ Josephson junctions, ${ }^{38}$ gates in metal epitaxial semiconductor field effect transistor (MESFET) technology,${ }^{39}$ diffusion barriers in $p / n$ junctions, ${ }^{40}$ and in $\mathrm{Cu} / \mathrm{Si}$ contacts. ${ }^{41,42}$ It is also worth notice their inert matrix in fast reactor fuels for incineration of plutonium and minor actinides. ${ }^{43}$

In spite of the large amount of bibliographic references available on these mononitrides, there are clearly very few studies on nitrides of elements of the group IV with the composition $\mathrm{Me}_{3} \mathrm{~N}_{4}$ (were Me represents the transition metal). In this respect, zirconium and hafnium nitrides show an interesting transformation from conducting to insulating phases, when composition changes from $\mathrm{MeN}$ to $\mathrm{Me}_{3} \mathrm{~N}_{4}$. This transformation is followed by a significant variation in their optical properties. It is also important to note that these changes from $\mathrm{MeN}$ metallic-type compounds toward the insulating $\mathrm{Me}_{3} \mathrm{~N}_{4}$-type phase are not easily achieved, mainly due to the relatively low reactivity of nitrogen toward the metallic element. ${ }^{44}$ Nevertheless $\mathrm{Me}_{3} \mathrm{~N}_{4}$ metastable phases have been observed, especially when using implantation or low energy ion-beam bombardment coupled with sputtering. ${ }^{45-47}$ One question that may arise is the possibility to tailor the film properties between those of metallic nitrides, $\mathrm{MeN}$, and those of a highly insulating phase. A route that is currently being investigated is the oxygen addition to the group IV elements. Examples on $\mathrm{TiN}^{48-50} \mathrm{TaN},{ }^{51} \mathrm{WN},{ }^{52} \mathrm{NbN},{ }^{53}$ $\mathrm{FeN},{ }^{54}$ and $\mathrm{ZrN}$ (Refs. 21, 55, and 56) are under intensive research, and available results show that tailoring of the behavior of the material from metallic type to insulating type by addition of the oxygen atom to the metallic $\mathrm{MeN}$ matrix seems to be an interesting approach.

Taking into account that the properties of the materials significantly depend on their interdependence of composition and type of bonds, structure, and morphology, an understanding of these relationships will be a major concern in this work. For this purpose, a set of $\mathrm{Zr}-\mathrm{O}-\mathrm{N}$ films was prepared and analyzed in terms of all the above items. This study will allow the establishment of limits for practical applicability of devices coated with these materials, providing new areas of application and supplying criteria for new material design for specific applications.

Moreover, this knowledge will be of major importance to understand the electrical behavior of the material and the nature of the metallic-to-insulating transition with increasing oxygen concentration. The main focus of this work is given to the understanding of the different phases that are formed in $\mathrm{ZrO}_{x} \mathrm{~N}_{y}$ ternary systems in comparison to those that are characteristic of $\mathrm{ZrO}_{x}$ and $\mathrm{ZrN}_{y}$ binary systems.

\section{EXPERIMENTAL DETAILS}

For the present work, $\mathrm{ZrO}_{x}, \mathrm{ZrN}_{y}$, and $\mathrm{ZrO}_{x} \mathrm{~N}_{y}$ films were deposited on glass and silicon (100) substrates by reactive dc magnetron sputtering, in a laboratory-sized deposition system. The deposition system is formed by two vertically opposed rectangular magnetrons (unbalanced of type 2 ), in a closed field configuration. The films were prepared with the substrate holder positioned at $70 \mathrm{~mm}$ from the target 
in all runs, using a de current density of $100 \mathrm{~A} \mathrm{~m}^{-2}$ on the zirconium target ( 99.6 at. \%). A gas atmosphere composed of argon+ nitrogen (for the preparation of the $\mathrm{ZrN}_{y}$ films) and argon +oxygen (for the preparation of the $\mathrm{ZrO}_{x}$ films) was used. For the preparation of the oxynitrides, $\mathrm{ZrO}_{x} \mathrm{~N}_{y}$, the gas atmosphere was composed of argon and a reactive $\mathrm{N}_{2}+\mathrm{O}_{2}$ gas mixture (17:3 ratio). The Ar flow was kept constant at 60 SCCM (SCCM denotes cubic centimeter per minute at STP) for all depositions. In the preparation of the $\mathrm{ZrO}_{x}$ system, the oxygen flow varied from 0.5 to 15 SCCM (corresponding to a partial pressure variation between $0.9 \times 10^{-2}$ and $1.2 \times 10^{-1} \mathrm{~Pa}$ ), while the nitrogen flow was varied from 3 to 40 SCCM (corresponding to a partial pressure variation between $9.9 \times 10^{-3}$ and $2.9 \times 10^{-1} \mathrm{~Pa}$ ) regarding the preparation of the $\mathrm{ZrN}_{y}$ thin films. In the case of the oxynitrides, the mixed reactive gas flow $\left(\mathrm{N}_{2}+\mathrm{O}_{2}\right)$ varied from 6 to 40 SCCM (corresponding to partial pressure variation between $7.8 \times 10^{-3}$ and $3.2 \times 10^{-1} \mathrm{~Pa}$ ). The working pressure was approximately constant during the depositions (varying slightly between $\sim 0.4$ and $0.5 \mathrm{~Pa}$ ), with a vacuum pumping speed adjusted for $356 \mathrm{~L} \mathrm{~s}^{-1}$. The substrates were grounded and no external heating was used. The temperature evolution of the coated substrates (resulting from the deposition process itself) was monitored with a thermocouple placed close to the surface of the substrate holder. A delay time of $5 \mathrm{~min}$ was used before positioning the surface of the samples in front of the $\mathrm{Zr}$ target. This delay time was used to avoid target poisoning resulting from previous depositions and also to assure a practically constant deposition temperature of the substrates during film growth.

The atomic composition of the as-deposited samples was measured by Rutherford backscattering spectroscopy (RBS) using 1.4 and $1.75 \mathrm{MeV}$ and $2 \mathrm{MeV}$ for the proton and ${ }^{4} \mathrm{He}$ beams, respectively. The scattering angles were $140^{\circ}$ (standard detector, IBM geometry) and $180^{\circ}$ (annular detector), tilt angles of $0^{\circ}$ and $30^{\circ}$. Composition profiles for the asdeposited samples were generated using software code IBA NDF V8.1I. ${ }^{57}$ For the ${ }^{14} \mathrm{~N},{ }^{16} \mathrm{O}$, and ${ }^{28} \mathrm{Si}$ data, the cross sections given by Ramos et al. ${ }^{58}$ were used. The analyzed area was about $0.5 \times 0.5 \mathrm{~mm}^{2}$. In addition, for some samples, particle induced $\mathrm{x}$-ray emission measurements were performed to check for impurities. Ball cratering tests were used to measure the thickness of the samples (used for deposition rate determination). The characterization of the bond types was carried out in an x-ray photoelectron spectroscopy (XPS) spectrometer $(12 \mathrm{kV}, 20 \mathrm{~mA})$ from VG (ESCALAB 210). A non-monocromatized $\mathrm{Mg} K \alpha(1253.6 \mathrm{eV})$ source was used for the measurements. Both XPS core and valence band spectra were recorded after successive sputtering-clean processes with $\mathrm{Ar}^{+}$ions $\left(3.5 \mathrm{kV}, 30^{\circ}\right.$ incidence), until a stationary regime was reached, spectra were taken in the $\Delta E$ constant mode with a pass energy of $50 \mathrm{eV}$. Shirley algorithm was applied for background subtraction. ${ }^{59}$ In order to eliminate the "charging effect" in the XPS analysis, all spectra where the $\mathrm{N} 1 s$ peak was clearly observed were calibrated to $\mathrm{N} 1 s$ position of $-396.2 \mathrm{eV}$. This peak position is referred in literature as the energy of the $\mathrm{N} 1 s$ peak in $\mathrm{ZrO}_{x} \mathrm{~N}_{y}{ }^{60,61}$ Anyway, this is not the "ideal" calibration, since the $\mathrm{N} 1$ s energy peak should be different in $\mathrm{ZrN}, \mathrm{Zr}_{3} \mathrm{~N}_{4}$ and $\mathrm{ZrO}_{x} \mathrm{~N}_{y}$
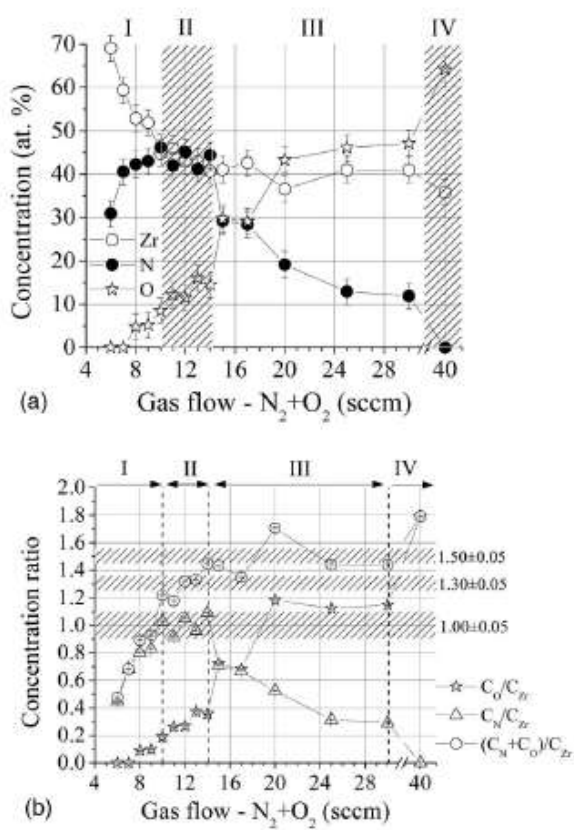

FIG. 1. (a) Variation of the atomic concentration of the films (deposited on Si substrates) as a function of the reactive gas flow. An average of 5 at. \% was estimated for the RBS concentration resolution. (b) Metalloid over the zirconium atomic ratios, $\mathrm{C}_{\mathrm{o}} / \mathrm{C}_{\mathrm{Zr}}, \mathrm{C}_{\mathrm{N}} / \mathrm{C}_{\mathrm{Zr}}$ and $\left(\mathrm{C}_{\mathrm{N}}+\mathrm{C}_{\mathrm{o}}\right) / \mathrm{C}_{\mathrm{Z}}$ as a function of the reactive gas flow. The uncertainty was determined by error propagation.

states. This choice results from two factors: (i) the inexistence of Ar peaks in some of the sputter-cleaned samples and, (ii) the surface oxide degradation of the samples. The peak located at $E_{B} \sim 396.2 \mathrm{eV}$ is referred in the literature as representative of $\mathrm{Zr}-\mathrm{N}$ bonds in $\mathrm{Zr}_{3} \mathrm{~N}_{4}$ phase, (Ref. 62 and 63) and to the $\mathrm{Zr}-\mathrm{O}-\mathrm{N}$ bond type in $\mathrm{ZrO}_{x} \mathrm{~N}_{y}$ compounds. Since zirconium and nitrogen can present similar ionic valences in zirconium oxynitride and in the $\mathrm{Zr}_{3} \mathrm{~N}_{4}$ form, ${ }^{61}$ the selected calibration should be the most adequate choice. The oxide coatings were calibrated to the $\operatorname{Ar} 2 p_{3 / 2}-242.6 \mathrm{eV}$ and $\mathrm{N} 1 s-396.2 \mathrm{eV}$.

The structure and phase distribution of the coatings were accessed by $\mathrm{x}$-ray diffraction (XRD), using a conventional Philips PW 1710 diffractometer, operating with $\mathrm{Cu} K \alpha$ radiation, in a Bragg-Brentano configuration. Electrical resistivity at room temperature and as a function of temperature was obtained in the Van der Pauw geometry for resistivity values lower than $1.82 \times 10^{6} \mu \Omega \mathrm{cm}$ and by $I-V$ curves, between $\mathrm{Al}$ parallel contacts, for higher resistivity values.

\section{RESULTS AND DISCUSSION}

\section{A. Composition}

Figure 1 shows the composition results obtained from the RBS spectra of the $\mathrm{ZrO}_{x} \mathrm{~N}_{y}$ samples (with thickness ranging from 2.8 to $6.2 \mu \mathrm{m}$ ), plotted as a function of the reactive gas flow rate. Figure 1(a) shows the variation of the atomic 
concentration of the film's elements as a function of the reactive gas mixture flow, and Fig. 1(b) represents the metalloid over the zirconium atomic ratios, $\mathrm{C}_{\mathrm{O}} / \mathrm{C}_{\mathrm{Zr}}, \mathrm{C}_{\mathrm{N}} / \mathrm{C}_{\mathrm{Zr}}$ and $\left(\mathrm{C}_{\mathrm{N}}+\mathrm{C}_{\mathrm{O}}\right) / \mathrm{C}_{\mathrm{Zr}}$. From Fig. 1(a), the first conclusion to be drawn is that there is a continuous increase of the oxygen content of the coatings with increasing gas flow rate, though a large amount of nitrogen is also present in the reactive gas mixture (it should be noted that the gas flow is composed of a mixture of $\mathrm{N}_{2}+\mathrm{O}_{2}$ with a fixed 17:3 ratio). This is due to the well-known high affinity of zirconium metal atoms toward oxygen rather than to nitrogen. ${ }^{64}$ Taking into account the available thermochemistry data for zirconium oxides and nitrides, a complete oxidation of the film would be expected as long as sufficient oxygen is available, since the formation of a zirconium-oxygen bond is energetically more favorable $\left[\Delta H_{f \mathrm{ZrO} 2}^{\circ}:-1042.8 \mathrm{~kJ} / \mathrm{mol}\right.$ Ref. 65] than that of a zirconium-nitrogen bond $\left[\Delta H_{f}^{\circ} \mathrm{ZrN}:-365.5 \mathrm{~kJ} / \mathrm{mol}\right.$ Ref. 66]. These results suggest that with the former deposition parameters, the kinetics of the reaction plays a dominant role.

Figure 1(a) also shows that it is possible to divide the films into distinct compositional regions according to the features of the plot. This figure shows that for reactive gas flows below 10 SCCM, composition analysis revealed an increase of the nitrogen content from $\sim 31$ to $\sim 43$ at. $\%$. and a systematic decrease of the zirconium content from abou 69 at. \% down to $\sim 52$ at. \%, corresponding to reactive gas flow variations from 6 to $9 \mathrm{SCCM}$, respectively. The amount of oxygen in the films within this region is relatively low, increasing steadily to approximately 6 at. $\%$.

At these low values of the reactive gas flow, almost all the available reactive gas is gathered at the condensation sites. As a result, the deposition rate is high (varying from about 8 to $10 \mu \mathrm{m} \cdot \mathrm{h}^{-1}$ and the deposited films are of typical metal-rich type. Nevertheless, the first two samples present almost no detectable oxygen by RBS (meaning that is most likely below 5 at. \%). This result is somewhat unexpected due to the high affinity of zirconium toward the oxygen, but it is certainly related with the RBS resolution, especially when small amounts of light elements are involved. Since the kinetics of the reaction presents a dominant role in this zone, it is expected that these samples present an atomic ratio of nitrogen to oxygen close to 5.7 , since the gas mixture is composed by $85 \%$ of nitrogen and $15 \%$ of oxygen. Taking as a reference, the samples prepared with reactive gas flows of 6 and 7 SCCM, the simulated values for the oxygen amount would be around 4.6 and 6.1 at.\%, respectively, which are close to the technique detection limit.

Furthermore, Fig. 1(b) shows that the metalloid over the zirconium atomic ratios, $\mathrm{C}_{\mathrm{O}} / \mathrm{C}_{\mathrm{Zr}}, \mathrm{C}_{\mathrm{N}} / \mathrm{C}_{\mathrm{Zr}}$, and $\left(\mathrm{C}_{\mathrm{N}}\right.$ $\left.+\mathrm{C}_{\mathrm{O}}\right) / \mathrm{C}_{\mathrm{Zr}}$, also increase with the gas flow rate. Particularly noticeable is the increase of the $\mathrm{C}_{\mathrm{N}} / \mathrm{C}_{\mathrm{Zr}}$ ratio, which approaches to one, and thus illustrating a possible tendency for the formation of substoichiomettric and stoichiometric $\mathrm{Zr}$ $\mathrm{N}$-type compounds. The $\mathrm{C}_{\mathrm{O}} / \mathrm{C}_{\mathrm{Zr}}$ ratio also shows a slight increase up to approximately 0.1 for the film prepared with a gas flow of 9 SCCM, indicating that some important changes in the film structure might have been developed.

Regarding the surface appearance, the films prepared within this first zone show color tones from metallic (silver-

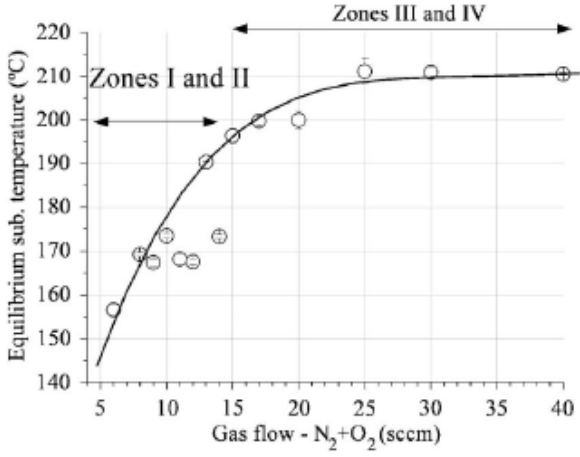

FIG. 2. Equilibrium substrate temperature as a function of the reactive gas mixture flow. The error was determined by the maximum deviation to the average value.

like) toward golden, which are characteristic of a change from metal-like to nitride-based compounds. ${ }^{67}$ Henceforth, these films will be noted as belonging to zone I.

For increasing gas flows between 10 and 14 SCCM, some changes in composition occur (see Fig. 1), characterized by an approximately constant concentration of both zirconium and nitrogen [Fig. 1(a)]. The amount of oxygen increases slightly from $\sim 9$ to $15-16$ at. $\%$. Within this second zone, which will be indexed in the text as belonging to zone II, the $\mathrm{C}_{\mathrm{N}} / \mathrm{C}_{\mathrm{Zr}}$ atomic ratio is roughly constant and close to one, but the $\mathrm{C}_{\mathrm{O}} / \mathrm{C}_{\mathrm{Zr}}$ atomic ratio increases from approximately 0.20 to $0.36-0.37$. The value of $\mathrm{C}_{\mathrm{N}} / \mathrm{C}_{\mathrm{Zr}}$ close to the unit would, in a first approximation, induces some tendency to form stoichiometric $\mathrm{ZrN}$ compounds, but the significant amount of oxygen that is present (between 9 and 16 at.\%) will certainly play a decisive role in the bonding characteristics of the films as well as in the crystalline/amorphous phase formation. One possibility is the increase of oxygen incorporation/substitution, in the zirconium nitride matrix, resulting in an overstoichiometric oxygen doped zirconium nitride structure. ${ }^{21,68}$ Nevertheless, the formation of oxidetype compounds must be regarded also as a possibility and must be taken into account. Another important factor is that one related to the sum of both nonmetals over the metal atomic ratio $\left(\mathrm{C}_{\mathrm{N}}+\mathrm{C}_{\mathrm{O}}\right) / \mathrm{C}_{\mathrm{Zr}}$ For the samples prepared within this second zone, this ratio increases from 1.22 to 1.45 due to the increased oxygen content. Since the coatings are deposited at low deposition temperatures (below $210^{\circ} \mathrm{C}$, Fig. 2, which is less than $14 \%$ of the $\mathrm{ZrN}$ melting point ${ }^{66}$ ) and without ion bombardment (no substrate bias was used), it is expected that the coatings do not present significant adatom mobility to assure phase segregations (nitride/oxides), reinforcing the possibility of having other types of compounds such as nonthermodynamic stable phases $\left(\mathrm{Zr}_{3} \mathrm{~N}_{4}\right)$, which may also result from the doping of growing compounds. In good agreement with the particular constancy of both $\mathrm{N}$ and $\mathrm{Zr}$ atomic concentrations, the films prepared within this second zone revealed very similar values of deposition rate, which varied only slightly between $7 \mu \mathrm{m} \cdot \mathrm{h}^{-1}$ (for the film prepared with $10 \mathrm{SCCM}$ ) and $6.2 \mu \mathrm{m} \cdot \mathrm{h}^{-1}$ for the film pre-

JAP 104907-4 
pared with a gas flow of 14 SCCM. In terms of color tones, the samples prepared within zone II exhibited colors from red brownish toward dark blue.

For the samples deposited with reactive gas flows between 15 and 30 SCCM, Fig. 1(a) shows that similar to what was observed in zone II, the zirconium concentration is still approximately constant (only few oscillations were observed). However, there is a clear decrease in the nitrogen concentration from about 44 at. $\%$ at $14 \mathrm{SCCM}$ to $\sim 12$ at. $\%$ at 30 SCCM. This significant decrease is followed by an increase of the oxygen concentration from about 15 at. $\%$ at $14 \mathrm{SCCM}$ to about 30 at. $\%$ at 15 and $17 \mathrm{SCCM}$ and from about 43 to $\sim 47$ at. \% from 20 to $30 \mathrm{SCCM}$ These changes correspond to a substantial increase of the $\mathrm{C}_{\mathrm{O}} / \mathrm{C}_{\mathrm{Zr}}$ atomic ratio, which lies close to 0.7 for the first samples of this zone (15 and $17 \mathrm{SCCM}$ ) and then close to 1.2 for the others. The values of the $\mathrm{C}_{\mathrm{N}} / \mathrm{C}_{\mathrm{Zr}}$ ratio decrease significantly from 0.7 to $\sim 0.3$ as a consequence of the decrease of nitrogen concentration, but there is roughly a stabilization of the nonmetal to metal atomic ratio $\left(\mathrm{C}_{\mathrm{N}}+\mathrm{C}_{\mathrm{O}}\right) / \mathrm{C}_{\mathrm{Zr}}$ at a value close to 1.5 . This evolution shows a very different behavior in comparison to that of zone II, suggesting a change on the atomic arrangements. Taking into account both the $\mathrm{C}_{\mathrm{N}} / \mathrm{C}_{\mathrm{Zr}}$ and $\mathrm{C}_{\mathrm{O}} / \mathrm{C}_{\mathrm{Zr}}$ ratios, it is rather difficult to predict any of the atomic compounds that may have been formed with these three elements. Further to this, the values of the nonmetal to metal atomic ratio $\left(\mathrm{C}_{\mathrm{N}}+\mathrm{C}_{\mathrm{O}}\right) / \mathrm{C}_{\mathrm{Zr}}(\sim 1.5$ in this zone) may be indicative of the formation of different compounds beyond $\mathrm{ZrN}$ and $\mathrm{ZrO}_{2}$. The existence of oxynitride compounds is one of the possibilities. The samples prepared within this third zone revealed a more pronounced decrease in deposition rate when compared to zone II, with values decreasing from $6 \mu \mathrm{m} \mathrm{h}^{-1}$ for the sample prepared with a gas flow of $15 \mathrm{SCCM}$ to $4 \mu \mathrm{m} \mathrm{h}^{-1}$ for the sample prepared with 30 SCCM. The surfaces of the samples have interferencelike tones, losing the characteristic intrinsic color revealed in the previous zones.

Finally, the samples deposited with the higher values of the reactive gas flow (30 SCCM) show a stoichiometry close to that of zirconium oxide, $\mathrm{ZrO}_{2}$, with no detectable nitrogen by RBS. This can be interpreted by the progressive replacement of nitrogen by oxygen within the matrix due to its high reactivity. The undetectable presence of nitrogen suggests that the thermodynamic factors are now dominant with these deposition parameters. The samples prepared under these conditions will be indexed to zone IV throughout the text and keep the interference-like tones of previous zone, but with relatively lower deposition rates-about $2.3 \mu \mathrm{m} \cdot \mathrm{h}^{-1}$.

Similar trends of variation were also observed in the substrate equilibrium temperature of the films, Fig. 2. The growth temperature of the films varies from approximately 150 to $210^{\circ} \mathrm{C}$, with a good correlation with the previous different zones of composition. This figure shows that samples within zones I and II have temperatures that are roughly lower than those of zones III and IV. Moreover, it is also to note the almost constancy of deposition temperatures in the films from zone II, again in accordance with the results of composition. The different bond characteristics that are being formed, promoted by the different compositional ar-
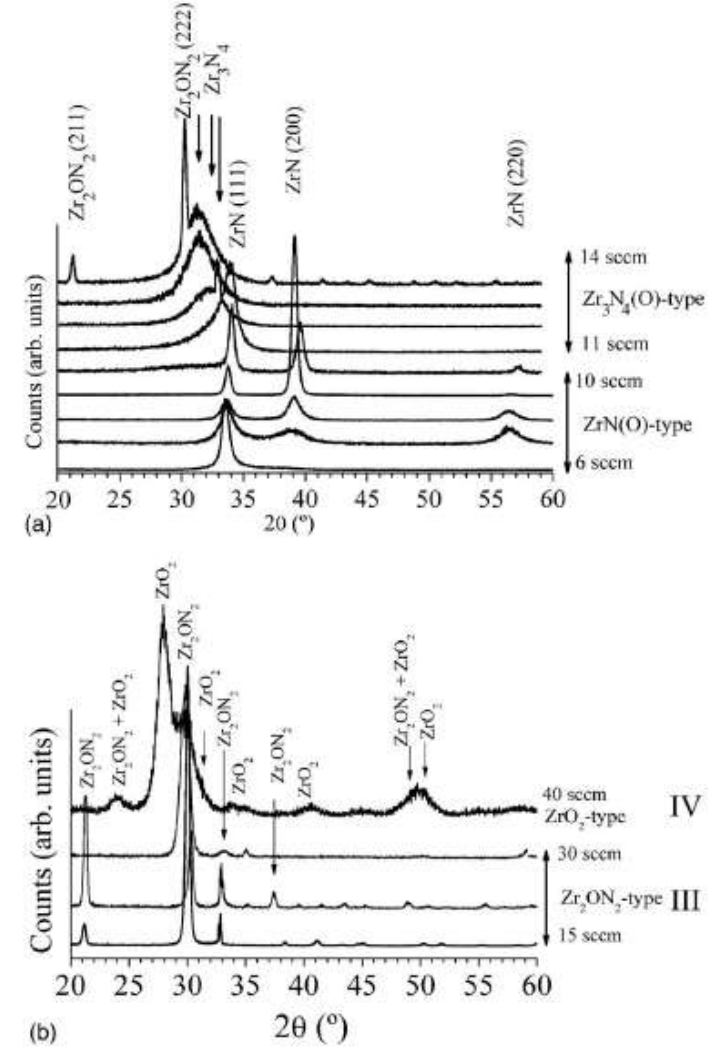

FIG. 3. (a) XRD patterns of the $\mathrm{ZrO}_{x} \mathrm{~N}_{y}$ samples (deposited on $\mathrm{Si}$ substrates) prepared within the first two composition zones. (b) XRD patterns of the $\mathrm{ZrO}_{x} \mathrm{~N}_{y}$ samples (deposited on $\mathrm{Si}$ substrates) prepared within zones III and IV.

rangements (nitride-based compounds versus oxide-like ones) are certainly playing an important role for these differences.

\section{B. Structure}

In order to follow the influence of variation to the chemical composition in the structural features of the films, a detailed structural characterization was carried out. Figures 3(a) and $3(\mathrm{~b})$ show the XRD patterns for samples prepared within the four different compositional zones where the differences in phase formation and orientation can be observed. Following the four composition zones, the structural analysis brings other insights, not only to confirm these distinct zones, but also uncovering the development of different crystalline structures. The films prepared within zone I, with values of composition ratios $\mathrm{C}_{\mathrm{N}} / \mathrm{C}_{\mathrm{Zr}}$ up to $\sim 0.8$ and $\left(\mathrm{C}_{\mathrm{N}}+\mathrm{C}_{\mathrm{O}}\right) / \mathrm{C}_{\mathrm{Zr}}$ $\sim 1$, the XRD patterns [Fig. 3(a)] revealed that they crystallize in a $\mathrm{B} 1-\mathrm{NaCl}$ crystal structure, typical for $\mathrm{ZrN}$, with a progressive change of the preferential growth from (111) to (200) with increasing reactive gas flow. The peak intensity ratio $\left[I_{200} /\left(I_{200}+I_{111}+I_{220}\right)\right]$ increases from $\sim 0$ for the sample prepared with a gas flow of $6 \mathrm{SCCM}$ to $\sim 0.5$ for the 
sample prepared with $8 \mathrm{SCCM}$ and about 0.9 at 9 SCCM. This texture change has long been the subject of extensive research. ${ }^{69,70}$ For the growth of transition metal nitrides by reactive sputter deposition, the interplay and competition among several related surface reactions and diffusion processes are claimed to determine film growth kinetics, surface morphology, film microstructure, and texture. ${ }^{71}$ It has been shown that kinetic parameters such as the ion-to-metal flux ratio play a decisive role for the variation of these film characteristics. ${ }^{72,73}$ In the case of the absence of ion bombardment, such as in this work, results suggest that the preferred orientation is determined by the overall lowest energy plane, which comes from a critical competition between the residual strain and surface energy. ${ }^{74}$

In general, all the dc sputtered $\mathrm{ZrN}_{y}$ thin films deposited under these conditions show strong $\langle 111\rangle$ preferred orientations compared to $\mathrm{ZrN}$ powders, where the (200) intensity is the highest as the $\mathrm{C}_{\mathrm{N}} / \mathrm{C}_{\mathrm{Zr}}$ ratio approaches to stoichiometry. ${ }^{69,74}$ Although (002) planes are the most stable ones, resulting from the minimum surface energy, the film growth by dc sputtering is highly dynamically controlled, so that (111) planes with faster growth rate dominate. ${ }^{75}$ This is also the case in this work for the films prepared with low gas flows. ${ }^{21}$ One possible explanation of the orientation change from $\langle 111\rangle$ to $\langle 200\rangle$ within zone $\mathrm{I}$ is that the continuous approach of composition toward stoichiometric condition $\left[\mathrm{C}_{\mathrm{N}} / \mathrm{C}_{\mathrm{Zr}}\right.$ and/or $\left(\mathrm{C}_{\mathrm{N}}+\mathrm{C}_{\mathrm{O}}\right) / \mathrm{C}_{\mathrm{Zr}}$ tend to 1 and higher values $]$ brings the system closer to its thermodynamically stable condition, and thus favors the $\langle 200\rangle$ growth. Mahieu et al. ${ }^{76}$ stated that the change from $\langle 111\rangle$ to $\langle 100\rangle$ can also be the result of distinct growth modes, such as the microstructure changes according to Thornton's zone model. ${ }^{77}$ In fact, the increase in flow rates and the consequent changes in the deposition rate (see previous section) are responsible for inducing these different morphological growth features and textures. The $\langle 200\rangle$ orientation within zone I reveals a significant decrease for the sample prepared with the highest gas flow (10 SCCM), where the (111) peak is already the most intense. This "sudden" change might be a direct result of the excess of atomic species ( $\mathrm{N}$ and/or $\mathrm{O}$ ) to form the $\mathrm{NaCl}$-type $\mathrm{ZrN}(\mathrm{O})$ structure. The growth rate of (200) grains is then inhibited further due to the lattice distortion or interstitial site occupancy by the excess nitrogen and/or oxygen atoms. In fact, for a fcc NaCl-type structure, growth of $\langle 200\rangle$ orientation needs more coalescent energy than $\langle 111\rangle$ orientation. ${ }^{78,79}$ Therefore, for films prepared with the highest flows and shown to developing this fcc-type structure (zone I), crystallization becomes difficult and the $\langle 200\rangle$ orientation tends to disappear from the $\mathrm{x}$-ray pattern. This was also the case observed in a series of $\mathrm{ZrN}_{y}$ films prepared with increasing nitrogen gas flows. These films revealed the same preferential growth change from $\langle 111\rangle$ to $\langle 200\rangle$ preferential growth (but for higher values of gas flows), which reinforces the role of oxygen within the $\mathrm{Zr}-\mathrm{O}-\mathrm{N}$ system.

Regarding the $\mathrm{x}$-ray diffractograms for films prepared with reactive gas flows between 10 and 14 SCCM, zone II, Fig. 3(a), the results suggest the development of a crystalline structure that does not seem to match with that of fcc $\mathrm{ZrN}$, revealing a smooth transition from fcc $\mathrm{NaCl}$-type structure (sample deposited with a reactive gas flow of 10 SCCM) of zone I toward a new one. The reduced number of diffraction peaks associated with a significant peak broadening does not allow a fully accurate indexing of this structure. The broadening of the peak at $2 \theta \approx 32.2^{\circ}$, may induce the beginning of the formation of an overstoichiometric nitride phase close to that of $\mathrm{Zr}_{3} \mathrm{~N}_{4}$, which would result from the small grain size and/or some reduction of the crystalline volume fraction of the coating or even to a superposition of several peaks predicted in this region for this structure. ${ }^{80}$ Regarding the first two samples of this zone (10 and 11 SCCM), the possibility of having a mixture of both $\mathrm{ZrN}(\mathrm{O})$ and a different type of grains must be assumed, as suggested by the large tail observed in the diffraction peak between $30^{\circ}$ and $35^{\circ}$. Results from glancing geometry experiments further attested this behavior, while a very broad peak around $56^{\circ}$ also appeared. ${ }^{21}$ Similarly, the results obtained for the $\mathrm{ZrN}_{y}$ system showed that not only the preferential growth change behavior is the same but also the shape of the diffraction peaks at the highest nitrogen flows is similar to those of zone II. Lamni et al ${ }^{81}$ have noticed similar behavior on magnetron sputtered $\mathrm{ZrN}_{y}$ thin films, claiming that for $y>1.27$, the XRD patterns suggest the development of a particular structural arrangement consisting on a mixture of defect-rich fcc $\mathrm{ZrN}$ and poorly crystallized $\mathrm{Zr}_{3} \mathrm{~N}_{4}$. Nevertheless, it is important to notice the differences in the gas flows that are needed to trigger these structural changes, which were significantly higher for the prepared $\mathrm{ZrN}_{y}$ system [it was observed that it only started at 30 and $40 \mathrm{SCCM}$, in comparison to 10 for the $\mathrm{ZrO}_{x} \mathrm{~N}_{y}$ system, Fig. 3(a)]. Thus, it is clear that oxygen is playing a fundamental role on this behavior, indicating that this "early" phase change in the $\mathrm{ZrO}_{x} \mathrm{~N}_{y}$ system could be the result of some kind of "catalytic" effect of oxygen atoms incorporated in the nitride lattice. This oxygen doping, which is also facilitated by the low mobility of impinging species at the growing film, low temperature and unbiased conditions, would then lead to the formation of an oxygen doped zirconium nitride phase (also with possible nitrogen interstitials), resulting in a structure close to that of $\mathrm{Zr}_{3} \mathrm{~N}_{4},{ }^{68}$ as claimed by other authors in the $\mathrm{ZrN}_{y}$ system. The diffraction peak at $2 \theta \approx 32.2^{\circ}$ would then correspond to the (320) plane of the doped $\mathrm{Zr}_{3} \mathrm{~N}_{4}$-type structure or even to a mixture of several peaks. The peak at $2 \theta \approx 56^{\circ}$ could relate or be a mixture of diffraction peaks predicted for the $\mathrm{Zr}_{3} \mathrm{~N}_{4}$-type structure in the region $2 \theta=54^{\circ}-56^{\circ} .^{68}$ Other authors have already indicated the shift of the (111) peak of the $\mathrm{ZrN}$ (NaCl-type phase) toward smaller angles for films prepared with high nitrogen flows, ${ }^{46,82}$ which resulted in the development of a poorly crystallized $\mathrm{Zr}_{3} \mathrm{~N}_{4}$ phase. Furthermore, the flow rate used for the preparation of "pure" stoichiometric $\mathrm{ZrN}$ was about 6.5 SCCM, and in the case of films from zone II, the reactive gas flows were between 10 and 14 SCCM. From Fig. 1(b), it was also observed that the ratio $\mathrm{C}_{\mathrm{N}}+\mathrm{C}_{\mathrm{O}} / \mathrm{C}_{\mathrm{Zr}}$ in this zone varies between $\sim 1.2$ and 1.4 , and the atomic ratio $\mathrm{C}_{\mathrm{N}} / \mathrm{C}_{\mathrm{Z}}$ is close to 1 , much lower than that of $\mathrm{Zr}_{3} \mathrm{~N}_{4}$ compound. ${ }^{46,70,82}$ This may also be an indication that if the $\mathrm{Zr}_{3} \mathrm{~N}_{4}$-type phase is developed, it probably involves oxygen. The $\mathrm{ZrN}_{y}$ system only reveals a clear $\mathrm{ZrN}$-type structure for these amounts of gas flow (pure nitrogen). According to some authors, this

JAP 104907-6 
$\mathrm{Zr}_{3} \mathrm{~N}_{4}$ phase (orthorhombic) is formed as a result of cell expansion by incorporation of nitrogen (and oxygen) atoms in interstitial positions. ${ }^{45,68,83,84}$ Other authors have described it as a relaxed $\mathrm{NaCl}$ structure with some $\mathrm{Zr}$ vacancies. ${ }^{46}$

The development of overstoichiometric type of structures in the heaviest metal nitrides with the composition $\mathrm{Me}_{3} \mathrm{~N}_{4}$ has being discussed in literature, and it is known and widely accepted that there is a tendency toward an increased stability of heavier transition metals, when chemical bonds are established, that correspond to highest oxidation states. This is due to relativistic effects. ${ }^{85}$ For example, in the case of $\mathrm{Zr}$ and $\mathrm{Hf}$ nitrides, this enhanced stability of the +4 oxidation state in comparison to the common +3 allows the coexistence of the metallic nitride $\mathrm{MeN}$ (oxidation state +3 ) and insulating $\mathrm{Me}_{3} \mathrm{~N}_{4}$ (oxidation state +4 ) phases. ${ }^{68}$ For zirconium oxynitrides prepared by PVD techniques or by nitridation of $\mathrm{ZrO}_{2}$, the higher oxidation state $(+4)$ is stabilized. ${ }^{86}$ As a result, the stoichiometry of the oxynitrides tends to a "mixture" of $\mathrm{ZrO}_{2}$ with $\mathrm{Zr}_{3} \mathrm{~N}_{4}$ and this with $\mathrm{ZrN}$, rather than the constant development of a fcc ZrN-type phase (doped or pure). ${ }^{68}$ This might be a strong possibility in regard to the films prepared within zone II. In accordance, and due to the growing amount of oxygen within this second zone, one cannot disclose the possibility to have a very thin amorphous oxide phase, most likely within grain boundaries. Similar to the sample deposited with $10 \mathrm{SCCM}$ that appears to be a "transition sample" between the two crystalline phases already described, the sample deposited with 14 SCCM, presents not only the $\mathrm{Zr}_{3} \mathrm{~N}_{4}$ phase but also traces of another crystalline phase, the predominant phase of the coatings lying in the third zone.

With further increase of the reactive gas flow from 15 to $30 \mathrm{SCCM}$ in the $\mathrm{Zr}-\mathrm{O}-\mathrm{N}$ system, the composition shows an abrupt increase of the oxygen content [Fig. 1(a)], as well as on the $\mathrm{C}_{\mathrm{N}} / \mathrm{C}_{\mathrm{Zr}}$ and $\mathrm{C}_{\mathrm{O}} / \mathrm{C}_{\mathrm{Zr}}$ ratios. These changes are well correlated with the formation of another structure, which is observed by the change in the diffraction patterns [Fig. 3(b)], if compared to those of films from zones I and II [Fig. 3(a)]. With the deposition conditions of zone III (gas flows from 15 up to $30 \mathrm{SCCM}$ ), the diffraction patterns (including the very small ones) correspond to a cubic structure, which can be indexed to that of $\gamma-\mathrm{Zr}_{2} \mathrm{ON}_{2}$ (ICDD card No. 48-1635). ${ }^{61,86,87}$ An analysis of film composition ratios shows that the ratio $\mathrm{C}_{\mathrm{N}} / \mathrm{C}_{\mathrm{Zr}}$ in the films from zone III decreases from about 0.8 down to approximately 0.3 , and that $\mathrm{C}_{\mathrm{O}} / \mathrm{C}_{\mathrm{Zr}}$ increases from about 0.7 in the first two samples to about 1.2 for the last ones. Taking into account that in stoichiometric $\mathrm{Zr}_{2} \mathrm{ON}_{2}$ compound, the ratios $\mathrm{C}_{\mathrm{N}} / \mathrm{C}_{\mathrm{Zr}}$ and $\mathrm{C}_{\mathrm{O}} / \mathrm{C}_{\mathrm{Zr}}$ are 1 and 0.5 , respectively, it is concluded that the films within zone III have different atomic arrangements within the cubic lattice, where again oxygen is playing a fundamental role. In fact, oxygen is always in excess, in contrast with the deficiency of nitrogen, providing some evidence that the films may have significant lattice substitution/replacement in the nitrogen positions. Clarke et al. ${ }^{88}$ claimed that this structure (cubic Bixbyite-type crystal structure ${ }^{89}$ ) is similar to that of fluorite type from cubic $\mathrm{ZrO}_{2}$, in which one-fourth of anion positions are unoccupied and two-thirds of the remaining oxygen atoms are replaced by nitrogen atoms. This ar-

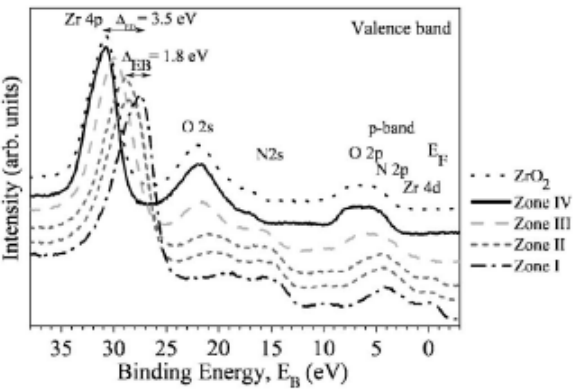

FIG. 4. XPS valence band spectra of $\mathrm{ZrO}_{x} \mathrm{~N}_{y}$ representative samples (deposited on Si substrates) within the four zones.

rangement means that in most oxynitrides $\mathrm{N}$ and $\mathrm{O}$ atoms are statistically disordered, and $\mathrm{Me}_{2} \mathrm{~N}_{2} \mathrm{O}$ can be formally considered as a $\mathrm{Me}_{2} \mathrm{X}_{3}$-type compound. ${ }^{88}$ For this group of samples, this could explain the formation of the $\mathrm{Zr}_{2} \mathrm{ON}_{2}$ structure with a stoichiometry varying from $\mathrm{ZrO}_{0.72} \mathrm{~N}_{0.71}$ (15 SCCM) to $\mathrm{ZrO}_{1.15} \mathrm{~N}_{0.29}$ (30 SCCM). In fact, Fig. 1(b) shows that the ratio $\left(\mathrm{C}_{\mathrm{N}}+\mathrm{C}_{\mathrm{O}}\right) / \mathrm{C}_{\mathrm{Zr}}$ varies between 1.4 and 1.5 (with one of the films presenting a value of about 1.7), which is very close to that of the $\mathrm{Zr}_{2} \mathrm{ON}_{2}$ compound (1.5). This fact provides some evidence for this "intermixing" of nitrogen and oxygen within the lattice.

Regarding the samples deposited with the highest reactive gas mixture flows (zone IV) and with a stoichiometry close to zirconium dioxide, $\mathrm{C}_{\mathrm{O}} / \mathrm{C}_{\mathrm{Zr}}$ is about 1.8 , x-ray diffractograms confirmed the oxide phase formation, revealing the existence of a monoclinic-zirconium oxide phase, $m-\mathrm{ZrO}_{2}$ (ICDD card No. 37-1484). This is somewhat expected since similar behavior was also observed in a series of $\mathrm{ZrO}_{x}$ films prepared with increasing of oxygen gas flows. Structural analysis on this series showed an evolution of the diffraction patterns from an oxygen doped $\mathrm{Zr}$ lattice (hcp type) toward that of monoclinic $\mathrm{ZrO}_{2}$.

\section{Bonding characteristics 1. XPS: Valence band}

Figure 4 shows experimental XPS valence band spectra for representative samples lying in the different zones previously identified. Assuming that there is no shift in the position of the Fermi energy, the valence band spectra characteristics of those four zones can be derived. The spectra are dominated by the $\mathrm{Zr} 4 p$ levels, but the O $2 s, \mathrm{~N} 2 s$, and molecular orbitals associated with $\mathrm{O} 2 p / \mathrm{N} 2 p$ and $\mathrm{Zr} 4 d$ valence levels can also be observed. Bazhanov et al. ${ }^{68}$ already reported that the valence band top in zirconium oxynitride is formed mainly by N $2 p$ orbitals, while the valence band bottom is composed of $\mathrm{O} 2 p$ orbitals, and that the conduction band in zirconium oxynitride structures consists predominantly of $\mathrm{Zr} 4 d$ orbitals, with also a significant contribution of $\mathrm{Zr} 4 d$ states to the valence band, indicating that the $\mathrm{Zr}-$ (O) $\mathrm{N}$ bonds in this compound have a significant covalent character.

The first important observation is that the $\mathrm{Zr} 4 p$ levels in the oxide zone (zone IV) appear chemically shifted by 
$\sim 3.5 \mathrm{eV}$ to higher binding energy with respect to the nitride (zone I). This shift is most likely due to the increase of the ionic character of the bonding. Moreover, some authors have claimed that the $\mathrm{Zr} 4 p$ in zirconium oxide present a shift of $\sim 4 \mathrm{eV}$ to higher binding energies regarding to the metal. ${ }^{90,91}$ In nitrides, the $\mathrm{Zr} 4 p$ core level exhibits an energy shift toward higher binding energy, being of about $1.5 \mathrm{eV}$ in the case of $\mathrm{Zr}_{3} \mathrm{~N}_{4}$-type films, if compared to the value of metallic zirconium. ${ }^{92}$ Associated with this shift of the $\mathrm{Zr}$ levels, there is also a decrease of the band at the Fermi level, until it disappears for samples lying in zone III (oxynitride-type films zone), and a parallel growth of a broad band at energies between 3 and $8 \mathrm{eV}$. This could indicate a progressive transfer of zirconium $4 d$ valence electrons to the $\mathrm{O} 2 p$ and $\mathrm{N} 2 p$ bands, until the complete depopulation of the $d$ band, the films becoming therefore insulator type. Associated with the decrease of the $d$ band at the Fermi levels is the decrease in intensity of the N $2 s$ peak and an increase of the $\mathrm{O} 2 s$, from films within zone I to those in zone IV. This variation is the result of film variation from $\mathrm{N}$ to $\mathrm{O}$ dominant. The difference in energy of the $2 s$ peaks ( $N 2 s$ and $\mathrm{O} 2 s$ ) reflects the increase in the nuclear charge, which results in contracted orbitals and lower-lying energy levels.

Also from Fig. 4, it is possible to determine the energy gap between the top of the valence band and the Fermi level of $\sim 5 \mathrm{eV}$ (energy distance between the $p$ band and Fermi level) for the films corresponding to zones III and IV, reinforcing the idea of a progressive tendency to form insulatingtype films. This could be interpreted from the large energy difference between the $\mathrm{O} 2 p$ and $\mathrm{N} 2 p$ bands and the nd orbitals that promotes an intrinsic gap between the $p$ and $d$ bands in the material. In contrast to fcc zirconium nitride (films within zone I), which is a metallic conductor, monoclinic zirconium oxide (and corresponding films from zone IV) is an insulator, with an electronic configuration of $4 d^{0}$ valence electrons located in the $\mathrm{O} 2 p$-derived band at energies between 4 and $11 \mathrm{eV}$, with a large energy difference between the $2 p$ and the $n d$ orbitals originating an intrinsic band gap. ${ }^{93}$

Finally, Fig. 4 also shows that the $p$ band is shifting to higher energies, followed by an increase of the O $2 s$ band. This could indicate that the hybridization between the $\mathrm{Zr} 4 d$ and $\mathrm{O} 2 p$ is increasing regarding to the $\mathrm{Zr} 4 d$ and $\mathrm{N} 2 p$ hybridization. In order to clarify this issue, Fig. 5 shows the subtraction spectrum between pairs of consecutive zones.

Plots from Figs. 5(a) and 5(b) show that there is a constant reduction of the $\mathrm{Zr} 4 d$ and $\mathrm{N} 2 p$ bands, followed by an increase of $\mathrm{O} 2 p$ band. According to previous studies, ${ }^{94-97}$ this evolution can be qualitatively interpreted as an increase of the transference of $d$-electrons from the band at the Fermi level to states between 6 and $9 \mathrm{eV}$ in the $\mathrm{O} 2 p$ band, together with a reduction of transference of $d$-electrons at the Fermi level to the $\mathrm{N} 2 p$ band, which would be the consequence of the oxygen increases in the first three zones. Again, this behavior can be well correlated with the decrease of the metallic and covalent character of the binding mechanisms and an increase of the ionic character, confirming the progressive change from nitride-type coatings (zone I) to oxide-type ones (zone IV).
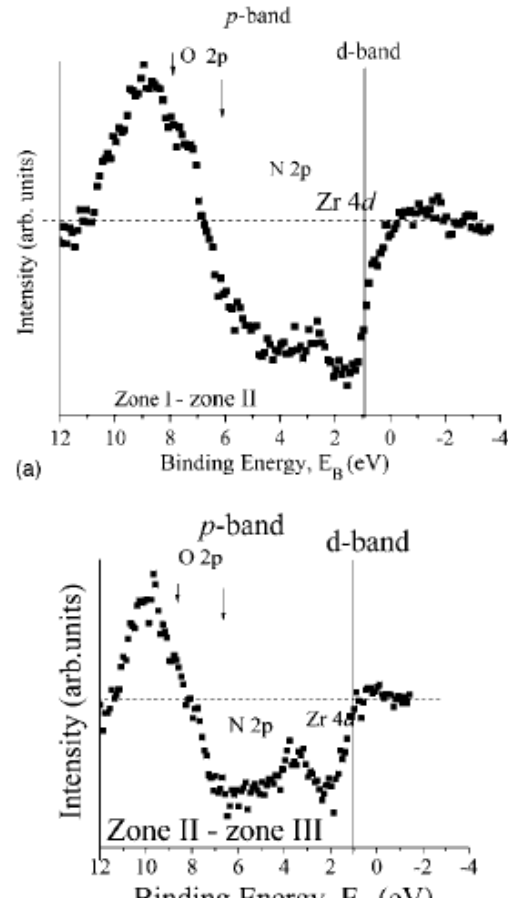

(b)

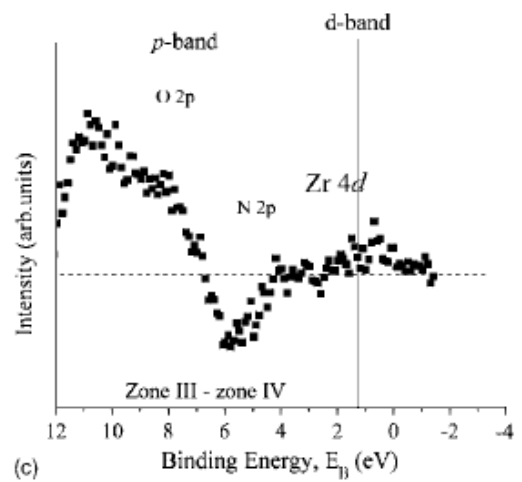

FIG. 5. Subtraction XPS valence band spectrum between pairs of samples from consecutive zones; (a) zone II-zone I samples; (b) zone III-zone II samples; (c) zone IV_-zone III samples.

These changes in the electronic structure will have a significant effect in the electrical behavior of the samples, as it will be shown later on in this work. Regarding the last plot [Fig. 5(c)], where the difference between the spectrums of zones III and IV is presented, it can be observed that there is no significant changes in the $d$ band at the Fermi level, since the $\mathrm{Zr} 4 d$ band is already completely depopulated. Moreover, there is a reduction of the N $2 p$ band and an increase of the O $2 p$ band, being again a sign of the increase in the ionic character of the binding mechanisms with the increase of the oxygen content. 


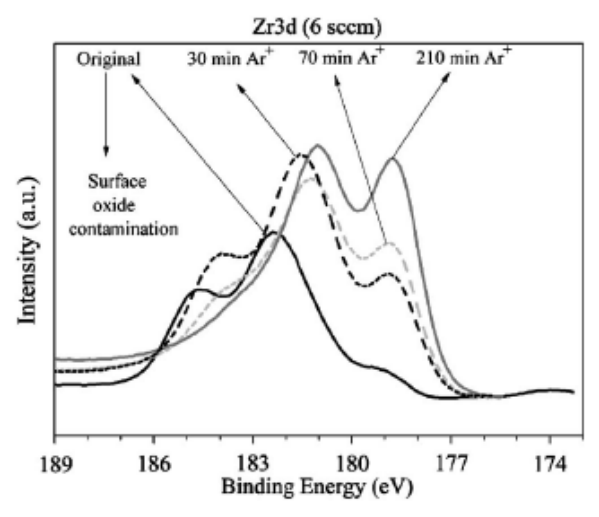

FIG. 6. XPS Zr $3 d$ spectra of different sputter-cleaning times for sample prepared with a reactive gas flow of 6 SCCM.

\section{XPS: Core}

One of most common sources of errors in XPS interpretation comes from surface contamination. Foord et al. ${ }^{98}$ studied the absorption of oxygen on polycrystalline zirconium and they suggest that oxygen absorbs dissociatively at $300 \mathrm{~K}$ and is immediately incorporated into the first few atomic layers of the solid. In the case of zirconium oxynitrides, this contamination layer is normally of zirconium oxide, which may lead to a misunderstanding in the identification of chemical states. In order to overcome this problem, a sputtercleaning procedure was adopted in this work. The ion bombardment of the ternary system $\mathrm{ZrO}_{x} \mathrm{~N}_{y}$ causes the preferential sputtering of oxygen and nitrogen, inducing a metal rich surface, and promoting the appearance of substoichiometric phases where zirconium is in a oxidation state lower than +4 . In fact, Wiame et al. ${ }^{99}$ claimed the formation of several different zirconium suboxide phases. In order to minimize this problem, a moderate energy sputtered cleaning process was performed with $\mathrm{Ar}^{+}$ions $\left(3.5 \mathrm{kV}, 30^{\circ}\right.$ incidence), during relatively large periods of time (up to $200 \mathrm{~min}$ ), until a compositional stationary regime was achieved. It is, however, worth noticing that even after this cleaning process, there was still some surface degradation (Fig. 6) due to the high reactivity of oxygen with zirconium and the deposition parameters. The absence of ion bombardment induces less dense coatings, favoring the superficial oxide degradation. Del $\operatorname{Re}$ et al. already reported oxidized coatings through all the bulk for unbiased samples due to the high porosity of the coatings. 60

Figure 6 shows the XPS $\mathrm{Zr} 3 d$ spectra for different sputtering-cleaned times, for the sample prepared within zone I (gas flow of 6 SCCM). Some oxide degradation at the surface still remains, even after $210 \mathrm{~min}$ of sputter cleaning. The erosion rate estimated due to the $\mathrm{Ar}^{+}$bombardment is between 0.1 and $0.5 \mathrm{~A} \cdot \mathrm{min}^{-1}$, and thus on this basis, the 210 min of sputter cleaning should correspond to $\sim 10 \mathrm{~nm}$ erosion, which is less than $1 \%$ of the film thickness. The superficial oxide degradation is also visible in the composition results from XPS, obtained for the samples after the steady state has been reached by sputtering (Fig. 7). Never-

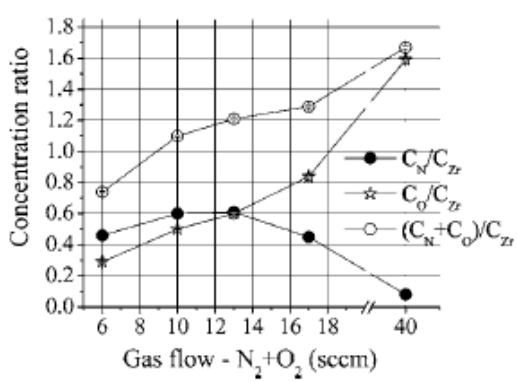

FIG. 7. XPS calculated metalloid over the zirconium atomic ratios, $\mathrm{C}_{\mathrm{O}} / \mathrm{C}_{\mathrm{Zr}}$ $\mathrm{C}_{\mathrm{N}} / \mathrm{C}_{\mathrm{Zr}}$ and $\left(\mathrm{C}_{\mathrm{N}}+\mathrm{C}_{\mathrm{O}}\right) / \mathrm{C}_{\mathrm{Zr}}$ as a function of the reactive gas flow. The results $\mathrm{C}_{\mathrm{N}} / \mathrm{C}_{\mathrm{Zr}}$, and $\left(\mathrm{C}_{\mathrm{N}}+\mathrm{C}_{\mathrm{O}}\right) / \mathrm{C}_{\mathrm{Zr}}$ as a function of the reactive gas flow. The results
were obtained after the steady state has been reached by sputter cleaning. The error was determined by error propagation.

theless, the $\mathrm{Ar}^{+}$bombardment induces a preferential sputtering of oxygen and nitrogen, the analyzed area by XPS for all the films shows more oxygen than that of the "bulk" measured by RBS [Figs. 1(a) and 1(b)].

Figure 8 shows the $\mathrm{Zr} 3 d$ spectrum for selected samples prepared within each of the four zones and a $\mathrm{Zr} 3 d$ spectrum of a monoclinic- $\mathrm{ZrO}_{2}$ subjected to the same sputtering treatment $\left(3.5 \mathrm{kV}, 30^{\circ}\right)$, for reference. The high number of species of $\mathrm{Zr}$ with different oxidation states, induced by the ion bombardment or proper states of the film, does not allow an accurate deconvolution of the $\mathrm{Zr} 3 d$ XPS spectra obtained to show the presence of zirconium in different chemical states; nitride, oxynitride, and oxide. ${ }^{60,100,101} \mathrm{The} \mathrm{Zr} 3 d_{5 / 2}$ peak at $\sim 178.8 \mathrm{eV}$ corresponds to $\mathrm{Zr}-\mathrm{N},{ }^{99}$ and the related peak located at $E_{B} \sim 181.5 \mathrm{eV}$ is commonly attributed to $\mathrm{ZrO}_{x} \mathrm{~N}_{y^{*}}{ }^{91}$ The last peak is close to $182.5 \mathrm{eV}$, which is commonly observed for $\mathrm{ZrO}_{2}$ compounds. ${ }^{99}$ It must be noticed that the $\mathrm{Zr}$ $3 d$ spectrum of the sample deposited with 40 SCCM presents a very similar spectrum regarding the reference sample of mon- $\mathrm{ZrO}_{2}$, confirming that the $\mathrm{Zr} 3 d_{5 / 2}$ peak at $182.5 \mathrm{eV}$ represents a zirconium oxide phase. ${ }^{99}$

Another relevant feature from Fig. 8 is related with the reduction of the $\mathrm{ZrN}$ phase contribution, when going from samples within zone I toward those of zone III. The $\mathrm{ZrN}$ contribution completely vanishes for the samples within zone IV. This fact is consistent with the XRD analysis, where no

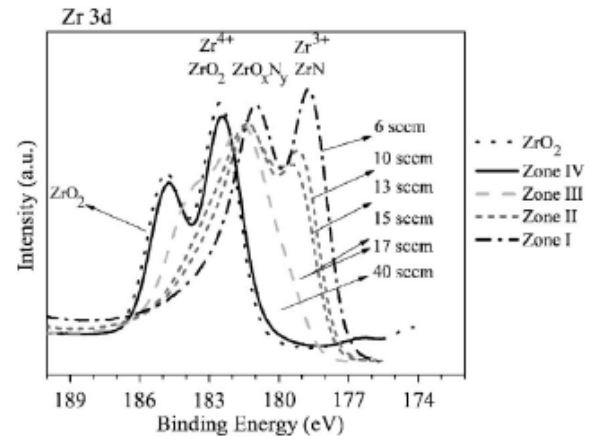

FIG. 8. $\mathrm{Zr} 3 d$ spectrum for selected samples prepared within each of the four zones, after the steady state has been reached by sputter cleaning. 
traces of $\mathrm{ZrN}$ phase were observed in zone IV. Together with the reduction of the $\mathrm{ZrN}$ contribution, Fig. 8 also shows a shift of $\sim 0.5 \mathrm{eV}$ of that $\mathrm{ZrN}$ peaks to higher binding energies. This shift to higher binding energies of a core electron is correlated to the change in the ionic valences induced by the chemical environment. ${ }^{102,103}$ Sanz et al. proposed that for nitride compounds, the XPS binding energy shift is due to the increase of oxygen that is incorporated within the nitride matrix ${ }^{90}$ which is consistent with the case of this work, where an increased oxygen amount is found when going from zone I to zone IV. With increasing oxygen content and the consequent continuous depopulation of the $d$ band at the Fermi level, the core electrons of zirconium will be attracted more tightly by the protons in the nuclei, which cause an increase of the binding energy of core electrons.

From Fig. 8 it is also clear that beyond the $\mathrm{Zr}-\mathrm{N}$ bonds, another important contribution for the overall behavior of the samples in zones II and III comes from a different kind of zirconium bonding: the so-called oxynitride-type bonding, $\mathrm{Zr}-\mathrm{O}-\mathrm{N}$. Regarding this contribution, it must be stated that it could represent several contributions resulting from different zirconium chemical environments with slightly different $\mathrm{O}$ and $\mathrm{N}$ contents. It is, therefore, extremely difficult to index this contribution either to actual film bonds or to surface contaminations. Milošev et al. ${ }^{61}$ claimed the later possibility, since the formation of several different zirconium suboxides $\left(\mathrm{Zr}_{2} \mathrm{O}, \mathrm{ZrO}, \mathrm{Zr}_{2} \mathrm{O}_{3}\right.$, and $\left.\mathrm{ZrO}_{2}\right)$ can occur during the interaction of zirconium with oxygen. ${ }^{63,104}$ Nevertheless, it is difficult to accurately propose the origin of these oxides. In recent works, Grafouté et $a l .{ }^{54}$ reported by Mössbauer spectrometry that, in $\mathrm{FeON}$ system, the environments of metal sites in these oxynitride films must be modeled by means of a binomial distribution of oxygen atom as first neighbors and are surrounded both by nitrogen atoms and at least one atom of oxygen or oxygen or vacancies.

It is also worth mentioning that this $\mathrm{Zr} 3 d$ doublet, referred here as "oxynitride component," is also pointed by Prieto et al.$^{101}$ to be representative of $\mathrm{Zr}-\mathrm{N}$ bonds correspondent to overstoichiometric zirconium nitride: $\mathrm{Zr}_{3} \mathrm{~N}_{4}$. This is probably due to the fact that zirconium presents similar chemical states in both insulating phases of oxynitride and overstoichiometric zirconium nitride $\left(\mathrm{Zr}_{3} \mathrm{~N}_{4}\right)$. Bazhanov et al. ${ }^{68}$ reported that, in oxynitrides, the higher $(+4)$ oxidation state is stabilized, such as the case of $\mathrm{Zr}_{3} \mathrm{~N}_{4}$.

Figure 9 shows the $\mathrm{N} 1 s$ spectra for selected samples prepared within each of the four zones. The oxide degradation of the analyzed area is also reflected in the shape of the $\mathrm{N} 1 s$ spectra. The dominant peak corresponding to nitride $(\mathrm{ZrO})-\mathrm{N}^{3-}$ in $\mathrm{ZrO}_{x} \mathrm{~N}_{y}$ oxynitride appears at a lower binding energy $(396.2 \mathrm{eV})$, regarding the characteristic $\mathrm{N} 1 s$ nitride peak, which normally appears at $397.8 \mathrm{eV}{ }^{61}$ This fact might be the result of the already referred oxide degradation of the analyzed area or representing the characteristic binding energy of the $(\mathrm{ZrO})-\mathrm{N}^{3-}$ in $\mathrm{ZrO}_{x} \mathrm{~N}_{y}$ oxynitride phase. The sample representative of zone IV only presents a residual $\mathrm{N}$ $1 s$ signal, also consistent with the composition and structural analyses.

Other authors claimed that in zirconium oxynitride, the $\mathrm{N} 1 s$ spectrum contains not only the peak at $E_{B} \sim 396.2 \mathrm{eV}$

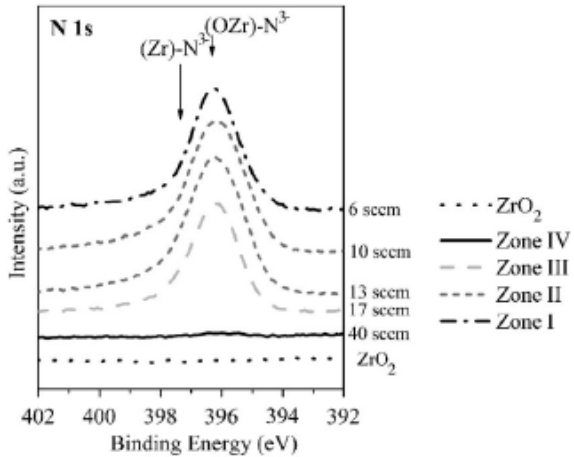

FIG. 9. N $1 s$ spectra for selected samples prepared within each of the four zones, after the steady state has been reached by sputter cleaning.

but also another one at $E_{B} \sim 400.1 \mathrm{eV} . .^{98,102}$ In our case, the samples sputter-cleaned showed no evidences of other peaks at higher energies. However, some of the "noncleaned samples" (gas flows of 6,10, and 13 SCCM) present a secondary peak at $\sim 400 \mathrm{eV}$ (Fig. 10). The intensity of this signal is not correlated with composition of the films, and it is fully and very soon removed by the sputter-cleaning process. This species has been previously ${ }^{105}$ detected in a $\mathrm{Zr}$ electrode, when oxidized by electrochemical surface nitriding with $\mathrm{LiCl}-\mathrm{KCl}-\mathrm{Li}_{3} \mathrm{~N}$, since no special care was taken to avoid surface oxidation of the sample after electrolysis. Milošev et al., ${ }^{61}$ working on $\mathrm{ZrN}$ exposed to atmosphere, found three components of the $\mathrm{N} 1 s$ spectra: the main nitride peak at $397.3 \mathrm{eV}$; a peak at lower binding energies $(\sim 396.3 \mathrm{eV})$ attributed to an "oxynitride peak," and a third peak at higher binding energies $(\sim 400 \mathrm{eV})$, which was also indexed to an oxynitride peak. Nevertheless, after surface sputter-cleaning the oxynitride peaks in the nitrogen signal disappeared and only the main nitride peak remained. Similar results on $\mathrm{TiN}$ coatings were obtained by several other authors. ${ }^{106-108}$ On this base it is possible to suggest that the $\mathrm{N}$ $1 s$ peak at $\sim 400 \mathrm{eV}$ should result from the surface contamination, and it is not a characteristic peak of $\mathrm{N} 1 s$ spectra in the $\mathrm{ZrO}_{x} \mathrm{~N}_{y}$ ternary system.

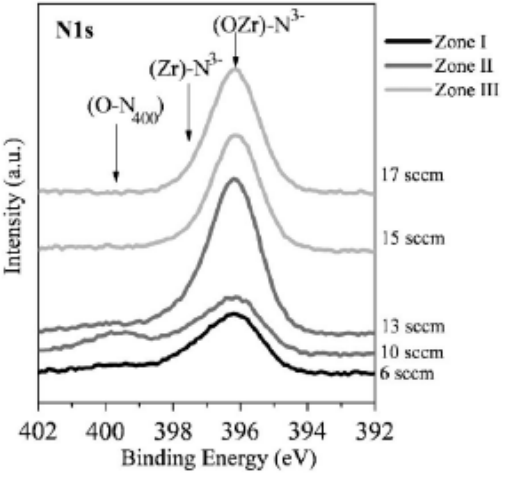

FIG. 10. N $1 s$ spectra for selected as-deposited samples, prepared within the first three zones.

JAP 104907-10 


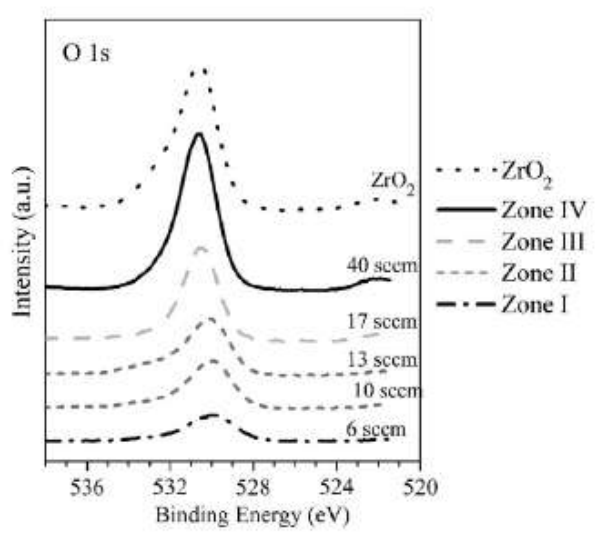

FIG. 11. $01 s$ spectra for selected samples, prepared within each of the fou zones, after the steady state has been reached by sputter cleaning. For comparison purposes, the figure also presents the $\mathrm{O} i s$ spectra for a monoclinic $\mathrm{ZrO}_{2}$ sample.

Figure 11 presents the $\mathrm{O} 1 s$ spectra for the representative samples in each of the four zones. From these results, it is possible to observe that the $\mathrm{O} 1 \mathrm{~s}$ spectrum presents a clear increase in intensity due to the increase of oxygen content Associated to the intensity increase is a shift of this $\mathrm{O}$ 1s peak to higher binding energies. This shift was also observed by Signore et al., ${ }^{109}$ when studying zirconium oxynitride thin films. These authors observed a shift to higher energies, not only in the $\mathrm{O} 1 s$ spectrums but also in the $\mathrm{N} 1 s$ peak. In this work, this was not the case since the binding energy scale was calibrated by the $\mathrm{N} 1 s$ peak at $E_{B} \sim 396.2 \mathrm{eV}$. Signore $e t$ al. claimed that the shift to higher energies of the $\mathrm{N} 1 s$ peak should result from the nitrogen replacement by oxygen in the $\mathrm{Zr}-\mathrm{N}$ network. ${ }^{109}$ Similar results were obtained by Mössbauer spectrometry on $\mathrm{FeON}$ films. ${ }^{54}$ These authors claimed a partial substitution of nitrogen atoms for oxygen atoms in the nitride network and that the oxynitride film does not contain any oxide phases. Due to a higher electronegativity of oxygen in comparison to that of nitrogen, the valence electrons of $\mathrm{N}$ atoms will move further from nuclei by surrounded $\mathrm{O}$ atoms. As a result, the core electrons will be attracted more tightly by the protons in the nuclei. Analogously, the binding energy of $\mathrm{O} 1 s$ also increases as a result of the decrease of surrounded $\mathrm{N}$ atoms. ${ }^{109}$

\section{Electrical resistivity}

Following both the composition and bonding character, the different zones previously identified can also be found in the resistivity behavior at room temperature (Fig. 12). The films from zone I revealed relatively low values of resistivity, ranging from $\sim 20 \mu \Omega \mathrm{cm}$ for pure $\mathrm{Zr}$ to values around $200 \mu \Omega \mathrm{cm}$ for the oxynitride films, which allows to index these films as of a "roughly" metallic type. These values are also consistent with those in the literature for both $\mathrm{Zr}$ and $\mathrm{ZrN}$ films. ${ }^{82,110}$ In this zone, the XPS valence spectrum, Fig. 4 , showed a nonvanishing $d$ band near the Fermi energy with an overlapping between the $d$ and $p$ bands. This nonvanishing DOS at the Fermi energy explains the metallic conduc-

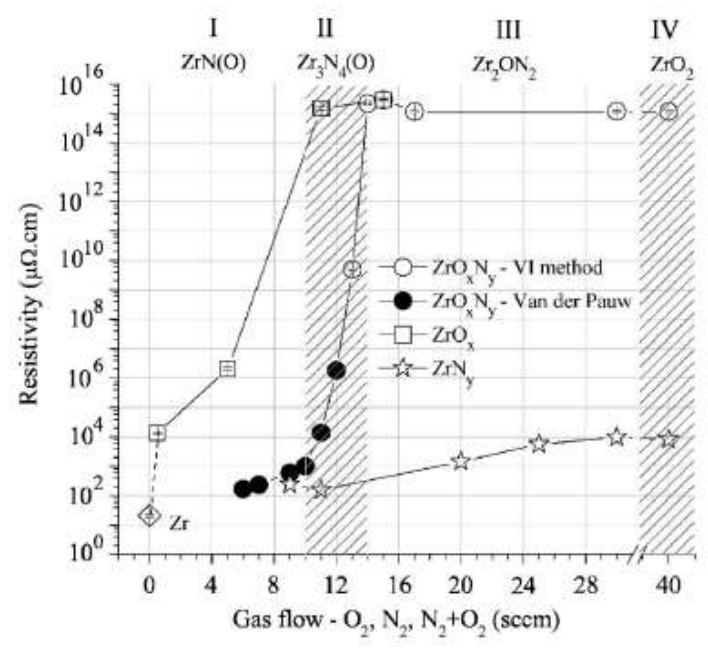

FIG. 12. Electrical resistivity variation at room temperature as a function of the reactive gases, for the oxynitride, nitride, and oxide series (films deposited on glass substrates). The error bar was determined by maximum deviation to the average value.

tivity of these films. ${ }^{100}$ Schwarz et al. ${ }^{35}$ also claimed that this overlapping of $p$ and $d$ bands is a sign of metallic-type materials. Moreover, the samples within this zone presented a small increase of resistivity with increasing temperature (Fig. 13), which can also be ascribed to the metallic-type conductivity.

The films allocated in zone II, where a poorly crystallized oxygen doped $\mathrm{Zr}_{3} \mathrm{~N}_{4}$-type phase was developed, showed the most interesting features, with the resistivity varying sharply from low metallic-type values (few hundreds of $\mu \Omega \mathrm{cm})$ to high-insulating-type ones $\left(10^{15} \mu \Omega \mathrm{cm}\right)$ at the highest gas flows. The composition analysis of the samples within this second zone [Figs. 1(a) and 1(b)] shows only slight changes in the $\mathrm{N}$ and $\mathrm{Zr}$ content, and the main important change seems to be in the $\mathrm{O}$ content, which varies from

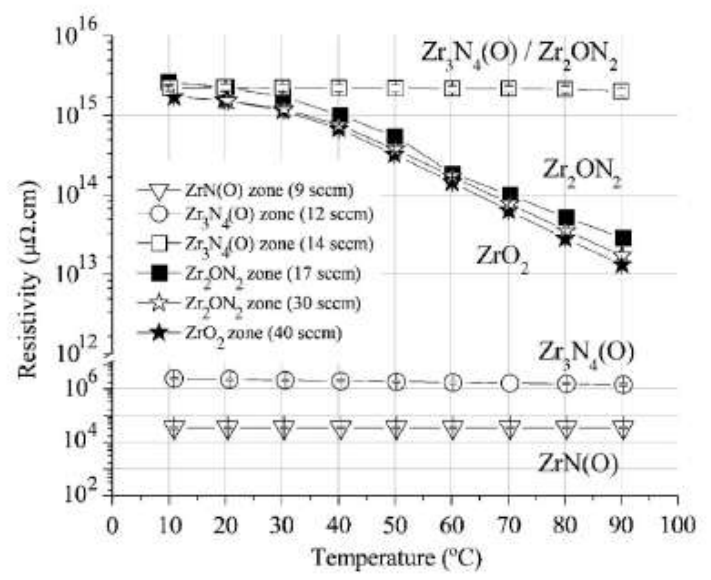

FIG. 13. Electrical resistivity evolution as a function of the temperature. The error bar was determined by maximum deviation to the average value.

JAP 104907-11 
$\sim 9$ at. $\%$ to approximately $15-16$ at. $\%$. Moreover, although the XRD data allowed the indexing of a doped $\mathrm{Zr}_{3} \mathrm{~N}_{4}(\mathrm{O})$ phase, some traces of $\mathrm{ZrN}$ phase could also exist, as evidenced by the significant peak broadening (samples deposited with 10 and 11 SCCM) within the samples of this zone [Fig. 3(a)]. Therefore, the fast increase of resistivity in this zone can be ascribed to the progressive change of an oxygendoped $\mathrm{ZrN}$-type structure toward a nitrogen +oxygen rich phase similar to that of $\mathrm{Zr}_{3} \mathrm{~N}_{4}$. Several authors reported a significant increase of electrical resistivity of $\mathrm{ZrN}$ thin films, when the $\mathrm{N} / \mathrm{Zr}$ ratio is approximately $1.2-1.3$, which results in the change of the structure of the film from a metallic-type $\mathrm{ZrN}$ phase to a insulating-type $\mathrm{Zr}_{3} \mathrm{~N}_{4}$ phase. ${ }^{82,92,110,111}$ This significant increase of electrical resistivity cannot be only attributed to the increase of oxygen [Figs. 1(a) and 1(b)] and the consequent increase of the ionic character of the bonds, since there is a similar oxygen increase in zone I [Figs. 1(a) and 1(b)], but with almost no effect in the electrical resistivity. Chappé et al. claimed that the increase of oxygen content and the increase of ionic bonding character are responsible for the smooth increase of electrical resistivity in the transition between nitride and oxide sputtering regimes for the TiN:O system. ${ }^{112}$

The behavior of the resistivity in nitrides is a very complex subject, depending not only on composition but also on parameters such as crystalline structure, morphology and density, among others. ${ }^{111,113,114}$ Liu and Yang reported that zirconium nitride coatings with rocksalt structure (such as the samples within zone I) and similar composition as the samples from zones I and II in this work revealed electrical resistivity varying roughly between $10^{3}$ and $10^{5} \mu \Omega \mathrm{cm}$. In the case of this work, the changes in structural features from zones I to II resulted in an increase of resistivity of about seven orders of magnitude (from $\sim 10^{3}$ to $10^{10} \mu \Omega \mathrm{cm}$, see Fig. 12). It is the electronic structure correlated to the compositional and structural features that explains the evolution of resistivity. Prieto et al. ${ }^{101}$ claimed that the change from metallic to insulating electrical behavior results from the complete depopulation of the $d$ band just below the Ferm level due to the large transference of $\mathrm{Zr} d$ electrons to nitrogen. In the same line, Sanz et al. ${ }^{92}$ claimed that the opening of a band gap in overstoichiometric zirconium nitride compounds, developing the $\mathrm{Zr}_{3} \mathrm{~N}_{4}$-type phase of zone II, could correspond to a percolation transition in which the incorporation of nitrogen atoms prevents the formation of $\mathrm{Zr}-\mathrm{Zr}$ paths, so that the conduction band minimum becomes determined by $\mathrm{Zr}-\mathrm{N}$ antibonding states, and the valence band maximum becomes determined by $\mathrm{N} 2 p$ bonding states. Furthermore, this author also claims that the intensity of the $d$ band at the Fermi level of zirconium nitride $\left(\mathrm{ZrN}_{y}\right)$ depends linearly on the average nitrogen content $(y)$, and the density of electrons per atom of zirconium (i.e., $n d$ ) could vary linearly according to the formula $n d=4-3 y$, with a complete suppression of the $d$ band for $y=1.33$ (i.e., in the presence of a $\mathrm{Zr}_{3} \mathrm{~N}_{4}$-type compound). In the case of this work, the complete depopulation of the $d$ band is not observed. Nevertheless the observed incomplete depopulation of the $d$ band could result form the sputtering cleaning process. This argument is reinforced by the observed negative slope in the
Arrhenius plot. A "real" noncomplete depopulation of the $d$ band should result in an opposite electrical behavior with temperature, and a decrease of electrical conductivity with increasing temperature should be observed.

Taking into account the composition plots (Fig. 1), it is possible to observe that zirconium and nitrogen still dominate in this region, with oxygen amounts lower than 15 at. \%. The temperature activation energy of the conductivity was calculated assuming a linear behavior in an Arrhenius plot of the conductivity as a function of the inverse temperature. ${ }^{112}$ The approximately constant low values of the activation energy regarding these samples (11 to 14 SCCM), associated with the continuous increase of electrical resistivity, can be explained with the decrease of free carrier concentration and/or mobility. The continuous increase of oxygen content in the $\mathrm{Zr}_{3} \mathrm{~N}_{4}$ insulating phase could explain the constancy of the electrical conductivity activation energies and the increase of the electrical resistivity in the manner that follows.

It is expected that a pure $\mathrm{Zr}_{3} \mathrm{~N}_{4}$ phase presents a higher DOS near the Fermi level than a $\mathrm{Zr}_{3} \mathrm{~N}_{4}(\mathrm{O})$ phase, since the presence of oxygen will induce a shift of the $p$ band to lower energy with the consequent transfer of part of the $\mathrm{Zr} d$ electrons near the Fermi level to the $\mathrm{O} p$ band and the concomitant decrease of transference to the $\mathrm{N} p$ band. Thus, it is expected that the lowest activation energy of the electrical conductivity should correspond to electronic transitions from states closer to the Fermi level, which for zirconium oxynitride correspond to states in the N $2 p$ bands. The XPS analysis confirms that, although there is an increased transference of $d$ electrons to the $\mathrm{O} 2 p$ band and a decreased transference to the $\mathrm{N} 2 p$ bands, there is not complete depopulation of the $\mathrm{N} 2 p$ band. On this basis it is possible to assume that the energy of the electrons available for electrical conductivity (in the $\mathrm{N} 2 p$ band) is the same in the samples deposited with reactive gas flows between 11 and 13 SCCM, giving rise to approximately equal values of activation energy, but with a decrease in their concentration (and possibly on the mobility too) that results in a lower conductivity.

Regarding the "transition" sample between zones II and III (sample deposited with 14 SCCM) which presents a mix between the $\mathrm{Zr}_{3} \mathrm{~N}_{4}$ and $\gamma-\mathrm{Zr}_{2} \mathrm{ON}_{2}$ structures, it was expected an increase of the activation energy due to the formation of the insulating phase with a higher band gap energy, the $\gamma-\mathrm{Zr}_{2} \mathrm{ON}_{2}$ phase. Bazhanov et al. ${ }^{68}$ claimed that the calculated DOS for the orthorhombic $\mathrm{Zr}_{3} \mathrm{~N}_{4}$ structure shows the semiconductor character of the material with the Fermi level located inside the energy band gap of $0.68 \mathrm{eV}$. The same authors ${ }^{68}$ claim an energy band gap of $1.5 \mathrm{eV}$ for the $\mathrm{Zr}_{2} \mathrm{ON}_{2}$ Bixbyite-type crystal structure. The reason for the constant activation energy of the conductivity regarding this sample should result from the percolation effect within the compound with the lowest activation energy, the $\mathrm{Zr}_{3} \mathrm{~N}_{4}$ structure.

The plot of the electrical resistivity as a function of the temperature (Fig. 13) also confirms the particular behavior of the samples from zone II. Although with resistivity values nine orders or magnitude higher than the first sample within this zone, the sample deposited with 14 SCCM shows no significant decrease of resistivity with the temperature.

JAP 104907-12 


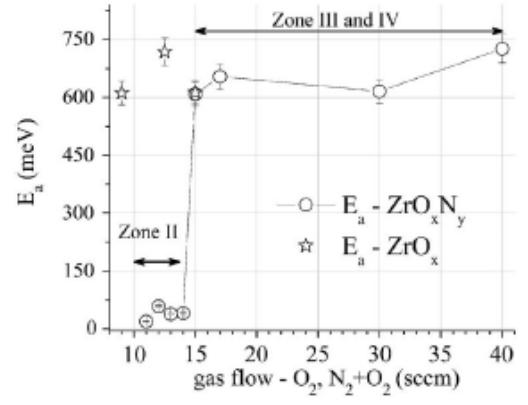

FIG. 14. Electrical conductivity activation energies $E_{a}$ as a function of the reactive gas flow for samples from zones II-IV. The error bar was determined by maximum deviation to the average value.

Comparing the evolution of the electrical resistivity of the zirconium oxynitride coatings with the zirconium nitride coatings (Fig. 12), it is possible to observe that the zirconium nitride coatings present only a much smaller and smooth increase of the electrical resistivity with the reactive gas flow $\left(\mathrm{N}_{2}\right)$. This difference is due to the fact that these films show a dominant conductive phase $(\mathrm{ZrN})$ and only a residual insulating phase, $\mathrm{Zr}_{3} \mathrm{~N}_{4}$ [Fig. 3(c)]

Within zones III and IV, the amount of oxygen is already significant and the tendency to have highly insulating phases, such as $\mathrm{Zr}_{2} \mathrm{ON}_{2}$ and $\mathrm{ZrO}_{2}$, is enhanced. Therefore, the films tend to be of electrically insulating nature. In these zones the samples show high values of the electrical resistivity and the conductivity is thermally activated (Fig. 14), as observed in zirconium oxide films. With the formation of the insulating phases of $\mathrm{Zr}_{2} \mathrm{ON}_{2}$ and $\mathrm{ZrO}_{2}$ and the progressive formation of a gap between the $p$ and $d$ bands, there is a thermal activated transport mechanism (Fig. 13).

\section{CONCLUSIONS}

$\mathrm{Zr}-\mathrm{O}-\mathrm{N}$ films were prepared by dc reactive magnetron sputtering, using a reactive gas mixture composed of $85 \%$

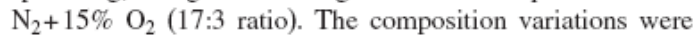
obtained by the increase of the gas flow, taking profit of the higher reactivity of oxygen to increase its content. The characterization of the composition variations (and especially the atomic ratios) allowed concluding about the existence of four different regions, which was shown throughout all characterizations that were consistent with the different behaviors that were observed. The electronic properties were a particular case of such influence.

These different regions were explained taking into account, firstly, the variations in the films elemental concentrations, which then was used to explain the films bonding structure and structural features. The combination of composition-bonding characteristics-structure was essential to understand the particular features of the electrical resistivity of the films.

Structural characterization revealed a strong dependence of the film texture on the oxygen content, exhibiting a change from a fcc B1 Nacl-type films for low gas flows (low oxygen contents) to develop a structure that might be similar to that of $\mathrm{Zr}_{3} \mathrm{~N}_{4}$, with oxygen inclusions, at intermediate gas flows (intermediate oxygen contents). For relatively high gas flows (high oxygen amounts), the films exhibited only crystalline structures that were indexed as oxynitride and oxide phases. These structural changes were straightly connected with the particular bonding characteristics of the films and also correlated with the electrical resistivity of the films. In terms of electronic structure, the films are ruled by the $\mathrm{Zr} 4 p$ levels, but the O $2 s, \mathrm{~N} 2 s$, and molecular orbitals associated with $\mathrm{O} 2 p / \mathrm{N} 2 p$ and $\mathrm{Zr} 4 d$ valence levels. Going from zone I to zone IV, the films present a progressive transfer of zirconium $4 d$ valence electrons to the $\mathrm{O} 2 p$ and $\mathrm{N} 2 p$ bands, with a shift to lower energies of the $p$ band, until the complete depopulation of the $d$ band where the films become an insulator-type material. The initial low values of resistivity were found to be related with the roughly metallic nature of the films, with compositions between that of $\mathrm{Zr}$ and substoichiometric $\mathrm{ZrN}(\mathrm{O})$. The resistivity of the films increased for reactive gas flows higher than $10 \mathrm{SCCM}$, which can be explained by the decrease the metallic bond contribution and the formation of oxygen-doped $\mathrm{ZrN}$ crystalline phase toward a nitrogen+oxygen rich phase, similar to that of $\mathrm{Zr}_{3} \mathrm{~N}_{4}$. Particularly noticeable was the result of electrical resistivity of films for intermediate gas flows (oxygen amounts between about 8 to 15 at. \%-zone II films), where in spite of almost no changes in $\mathrm{Zr}$ and $\mathrm{N}$ contents, the resistivity values increased about 12 orders of magnitude $\left(\sim 10^{3}\right.$ to $\left.\sim 10^{15} \mu \Omega \mathrm{cm}\right)$. The structural and bonding changes were found to be in accordance with these changes.

\section{ACKNOWLEDGMENTS}

This work was supported by the Portuguese Science Foundation "Fundação para a Ciência e Tecnologia" through the Project No. PTDC/CTM/69362/2006.

The authors P.C. and J.M.C. thank also the Portuguese Science Foundation "Fundação para a Ciência e Tecnologia" for the PhD Grant No. SFRH/BD/31907/2006 and postdoctoral Grant No. SFRH/BBD/27114/2006, respectively.

${ }^{1}$ W. Diehl, V. Sittinger, and B. Szyszka, Surf. Coat. Technol. 193, 329 (2005)

${ }^{2}$ R. Kassing, E. Oesterschulze, and W. Kulisch, Surf. Coat. Technol. 169_ 170, 237 (2003).

${ }^{3}$ H. K. Pulker, Surf. Coat. Technol. 112, 250 (1999).

${ }^{4}$ S. K. Pradhan, C. Nouveaua, A. Vasinb, and M.-A. Djouadi, Surf. Coat. Technol. 200, 141 (2005).

${ }^{5}$ A. N. Panckow, J. Steffenhagen, B. Wegener, L. Dübner, and F. Lierath, Surf. Coat. Technol. 138, 71 (2001).

${ }^{6}$ H. B. Chew, T. F. Guo, and L. Cheng, Thin Solid Films 504, 325 (2006).

${ }^{7}$ Q. Li, M. L. Amweg, C. K. Yee, A. Navrotsky, and A. N. Parikh, Microporous Mesoporous Mater. 87, 45 (2005)

${ }^{8}$ T.-L. Ren, H.-J. Zhao, L.-T. Liu, and Z.-J. Li, Mater. Sci. Eng., B 99, 159 (2003).

${ }^{9}$ A. Inberg, E. Ginsburg, Y. Shacham-Diamand, N. Croitoru, and A. Seidman, Microelectron. Eng. 65, 197 (2003).

${ }^{10}$ E. Reinhold, P. Botzler, and C. Deus, Surf. Coat. Technol. 120-121, 77 (1999).

${ }^{11}$ M. Jin Yim, and K. Wook Paik, Int. J. Adhes. Adhes. 26, 304 (2006)

${ }^{12}$ Z. L. Pei, X. B. Zhang, G. P. Zhang, J. Gong, C. Sun, R. F. Huang, and L. S. Wen, Thin Solid Films 497, 20 (2006).

${ }^{13}$ K. L. Choy, Prog. Mater. Sci. 48, 57 (2003)

${ }^{14}$ L. Hultman, Vacuum 57, 1 (2000).

${ }^{15} \mathrm{H}$. Heidsieck, Surf. Coat. Technol. 112, 324 (1999).

${ }^{16}$ S. Eliahou-Niv, R. Dahan, and G. Golan, Microelectron. J. 37, 302 (2006). 
${ }^{17}$ Z. Ji, J. Du, J. Fan, and W. Wang, Opt. Mater. (Amsterdam, Neth.) 28, 415 (2006).

${ }^{18}$ A. Schüler, J. Boudaden, P. Oelhafen, E. De Chambrier, C. Roecker, and J.-L. Scartezzini, Sol. Energy Mater. Sol. Cells 89, 219 (2005).

${ }^{19}$ S. Nakamura, Science 282, 956 (1998).

${ }^{20}$ S. Strite, and H. Morkoc, J. Vac. Sci. Technol. B 10, 1237 (1992)

${ }^{21}$ P. Carvalho, F. Vaz, L. Rebouta, L. Cunha, C. J. Tavares, C. Moura, E. Alves, A. Cavaleiro, Ph. Goudeau, E. Le Bourhis, J. P. Rivière, J. F Pierson, and O. Banakh, J. Appl. Phys. 98, 023715 (2005)

${ }^{22} \mathrm{~J}$. Vetter, G. Barbezat, J. Crummenauer, and J. Avissar, Surf. Coat. Technol. 200, 1962 (2005)

${ }^{23}$ B. W. Allcock, and P. A. Lavin, Surf. Coat. Technol. 163-164, 62 (2003)

${ }^{24}$ J. C. Kuang, C. R. Zhang, X. G. Zhou, and S. Q. Wang, J. Cryst. Growth 256, 288 (2003).

${ }^{25}$ R. R. Tummala, J. Am. Ceram. Soc. 74, 895 (1991)

${ }^{26} \mathrm{H}$. K. Pulker, Coatings on Glass, Thin Films Science and Technology (Elsevier, Amsterdam, 1984), Vol. 6, pp. 343-417.

${ }^{27} \mathrm{H}$. Bach and N. Neuroth, The Properties of Optical Glass, (Springer, Heidelberg, 1995), pp. 263-388.

${ }^{28}$ S. T. Oyama, Chemistry of Transition Metal Carbides and Nitrides, (Blackie Academic \& Professional, New York, 1996), pp. 215-309.

${ }^{29}$ J.-L. Calais, Adv. Phys. 26, 847 (1977).

${ }^{90}$ K. Schwarz, CRC Crit. Rev. Solid State Mater. Sci. 13, 211 (1987).

${ }^{31}$ S. Horita, T. Tujikawa T. H. Akahori, M. Kobayashi, and T. Hata, J. Vac Sci. Technol. A 11, 2452 (1993).

${ }^{32}$ A. Neckel, P. Rastl, R. Eibler, P. Weiberger, and K. Schwarz, J. Phys. C 9. 579 (1976).

${ }^{33}$ D. J. Singh and B. M. Klein, Phys. Rev. B 46, 014969 (1992).

${ }^{34}$ A. Neckel, Int. J. Quantum Chem. 23, 1317 (1983).

${ }^{35}$ K. Schwarz, H. Ripplinger, and A. Neckel, Z. Phys. B: Condens. Matter 48, 79 (1982)

${ }^{36}$ D. F. Arias, Y. C. Arango, and A. Devia, Appl. Surf. Sci. 253, 1683 (2006)

${ }^{37}$ T. Yotsuya, M. Yoshitake, and T. Kodama, Cryogenics 37, 817 (1997).

${ }^{3}$ K. Schwarz, A. R. Williams, J. J. Cuomo, J. H. E. Harper, and H. T. G. Hentzell, Phys. Rev, B 32, 8312 (1985)

${ }^{99}$ M. Wautelet, J. P. Dauchot, F. Debal, S. Edart, and M. Hecq, J. Mater. Res. 11, 825 (1996).

${ }^{40}$ Y. Igarashi, T. Yamaji, and S. Nishikawa, Jpn. J. Appl. Phys., Part 229 L2337 (1990).

${ }^{41}$ B. M. Takeyama, T. Itoi, E. Aoyagi, and A. Noya, Appl. Surf. Sci. 190, 450 (2002).

${ }^{42}$ B. M. Takeyama, A. Noya, and K. Sakanishi, J. Vac. Sci. Technol. B 18 1333 (2000).

${ }^{43}$ M. Burghartz, G. Ledergerber, H. Hein, R. R. Van der Laan, and R. J. M. Konings, J. Nucl. Mater. 288, 233 (2001).

${ }^{44}$ R. A. Andrievski, J. Mater. Sci. 32, 4463 (1997)

${ }^{45}$ B. O. Johansson, H. T. G. Hentzell, J. M. E. Harper, and J. J. Cuomo, J. Mater. Res. 1, 442 (1986)

${ }^{46}$ L. Pichon, T. Girarde au, A. Straboni, F. Lignou, P. Guérin, and J. Perrière, Appl. Surf. Sci. 150, 115 (1999).

${ }^{47}$ R. P. Netterfield, P. J. Martin, and D. R. McKenzie, J. Mater. Sci. Lett. 9. 972 (1990).

${ }^{48}$ J. M. Chappé, N. Martin, J. Lintymer, F. Sthal, G. Terwagne, and J. Takadoum, Appl. Surf. Sci. 253, 5312 (2007)

${ }^{49}$ F. Vaz, P. Cerqueira, L. Rebouta, S. M. C. Nascimento, E. Alves, Ph. Goudeau, J. P. Rivière, K. Pischow, and J. de Rijk, Thin Solid Films 447-448, 449 (2004)

${ }^{50}$ F. Vaz, P. Cerqueira, L. Rebouta, S. M. C. Nascimento, E. Alves, Ph. Goudeau, J. P. Rivière, Surf. Coat. Technol. 174-175, 197 (2003).

${ }^{51}$ H. Le Dréo, O. Banakh, H. Keppner, P.-A. Steinmann, D. Briand, and N F. de Rooij, Thin Solid Films 515, 952 (2006).

${ }^{52}$ N. M. G. Parreira, N. J. M. Carvalho, F. Vaz, and A. Cavaleiro, Surf. Coat. Technol. 200, 6511 (2006)

${ }^{53}$ M. Fenker, H. Kappl, O. Banakh, N. Martin, and J. F. Pierson, Surf. Coat Technol. 201, 4152 (2006)

${ }^{54} \mathrm{M}$. Grafoute, C. Petitjean, C. Rousselot, J. F. Pierson, and J. M. Grenèche, Scr. Mater. 56, 153 (2007)

${ }^{55}$ R. Franchy, Surf. Sci. Rep. 38, 195 (2000)

${ }^{56}$ F. Vaz, P. Carvalho, L. Cunha, L. Rebouta, C. Moura, E. Alves, A. R. Ramos, A. Cavaleiro, Ph. Goudeau, and J. P. Rivière, Thin Solid Films 469-470, 11 (2004).

${ }^{57}$ N. P. Barradas, C. Jeynes, and R. P. Webb, Appl. Phys. Lett. 71, 291 $(1997)$
${ }^{58}$ A. R. Ramos, A. Paúl, L. Rijniers, M. F. da Silva, and J. C. Soares, Nucl. Instrum. Methods Phys. Res. B 190, 95 (2002).

${ }^{59}$ QUASES-Tougaard Inc. Available from: www.quases. com

${ }^{60} \mathrm{M}$. Del Re, R. Gouttebaron, J.-P. Dauchot, P. Leclère, G. Terwagne, and M. Hecq, Surf. Coat. Technol. 174-175, 240 (2003).

${ }^{61}$ L. Milošev, H. H. Strehblow, M. Gaberscek, and B. Navinsěk, Surf. Interface Anal. 24, 448 (1996).

${ }^{62}$ J. M. Sanz, L. Soriano, P. Prieto, G. Tyuliev, C. Morant, and E. Elizalde, Thin Solid Films 332, 209 (1998)

${ }^{63}$ S. Tsunekawa, K. Asami, S. Ito, M. Yashima, and T. Sugimoto, Appl. Surf. Sci. 252, 1651 (2005)

${ }^{64}$ S. H. Mohamed, O. Kappertz, J. M. Ngaruiya, T. Niemeier, R. Drese, M. Wakkad, and M. Wuttig, Phys. Status Solidi A 201, 90 (2004).

${ }^{65}$ Handbook of Chemistry and Physics, 84 th ed. edited by D. R. Lide (CRC, Boca Roton, PL, 2003), pp. 5-23.

${ }^{66}$ X. Ma, C. Li, K. Bai, P. Wu, and W. Zhang, J. Alloys Compd. 373, 194 (2004).

${ }^{67}$ A. Rizzo, M. A. Signore, L. Mirenghi, and D. Dimaio, Thin Solid Films 515,1486 (2006)

${ }^{68}$ D. I. Bazhanov, A. A. Knizhnik, A. A. Safonov, A. A. Bagatur'yants, M.

W. Stoker, and A. A. Korkin, J. Appl. Phys. 97, 044108 (2005).

${ }^{69}$ D. Wu, Z. Zhang, W. Fu, X. Fan, and H. Guo, Appl. Phys. A: Mater. Sci. Process. 64, 593 (1997).

${ }^{70}$ D. Gall, S. Kodambaka, M. A. Wall, I. Petrov, and J. E. Greene, J. Appl. Phys. 93, 9086 (2003).

${ }^{71}$ L. Petrov, P. B. Barna, L. Hultman, and J. E. Greene, J. Vac. Sci. Technol. A 21, S117 (2003).

${ }^{72}$ L. Ivanov, P. Kazansky, L. Hultman, I. Petrov, and J.-E. Sundgren, J. Vac. Sci. Technol. A 12, 314 (1994).

${ }^{73}$ P. J. Kelly, and R. D. Arnell, J. Vac. Sci. Technol. A 16, 2858 (1998).

${ }^{74} \mathrm{~J}$. Pelleg, L. Z. Zevin, S. Lungo, and N. Croitora, Thin Solid Films 197. 117 (1991).

${ }^{75}$ M. M. Larijani, N. Tabrizi, Sh. Norouzian, A. Jafari, S. Lahouti, H. Haj Hosseini, and N. Afshari, Vacuum 81, 550 (2006).

${ }^{76}$ S. Mahieu, G. Winter, D. Depla, R. De Gryse, and J. Denul, Surf. Coat. Technol. 187, 122 (2004).

${ }^{n 7}$ J. A. Thornton, Annu. Rev. Mater. Sci. 7, 239 (1977).

${ }^{78}$ L. Hultman, J.-E. Sundgren, J. E. Greene, D. B. Bergstrom, and I. Petrov, J. Appl. Phys. 78, 5395 (1995).

${ }^{79}$ J. E. Greene, J.-E. Sundgren, L. Hultman, I. Petrov, and D. B. Bergstrom, Appl. Phys. Lett. 67, 2928 (1995).

${ }^{80}$ C. Moura, P. Carvalho, F. Vaz, L. Cunha, and E. Alves, Thin Solid Films $\mathbf{5 1 5}, 1132(2006)$

${ }^{81}$ R. Lamni, E. Martinez, S. G. Springer, R. Sanjinés, P. E. Schmid, and F. Lévy, Thin Solid Films 447-448, 316 (2004).

${ }^{82}$ H. M. Benia, M. Guemmaz, G. Scmerber, A. Mosser, and J. C. Parlebas, Appl. Surf. Sci. 211, 146 (2003)

${ }^{83}$ J. P. Dauchot, S. Edart, M. Wautelet, and M. Hecq, Vacuum 46, 927 (1995).

${ }^{84}$ M. Yoshitake, T. Nosaka, A. Okamoto, and S. Ogawa, Jpn. J. Appl. Phys., Part 2 32, L113 (1993)

${ }^{85}$ P. Pyykko, Chem. Rev. (Washington, D.C.) 88, 563 (1988)

${ }^{86}$ M. Lerch, J. Mater. Sci. Lett. 17, 441 (1998).

${ }^{87}$ H. Wiame, M.-A. Centeno, S. Picard, P. Bastians, and P. Grange, J. Eur. Ceram. Soc. 18, 1293 (1998).

${ }^{88}$ S. J. Clarke, C. W. Michie, and M. J. Rosseinsky, IEEE J. Solid-State Circuits 146, 399 (1999).

${ }^{89}$ E. Fuglein, R. Hock, and M. Lerch, Z. Anorg. Allg. Chem. 623, 304 (1997).

${ }^{90}$ C. Morant, J. M. Sanz, L. Galán, L. Soriano, and F. Rueda, Surf. Sci. 218, 331 (1989).

${ }^{91}$ C. Palacio, J. M. Sanz, and J. M. Martnez Duart, Surf. Sci. 191, 385 (1987).

${ }^{92}$ J. M. Sanz, L. Soriano, P. Prieto, G. Tyuliev, C. Morant, and E. Elizalde, Thin Solid Films 332, 209 (1998)

${ }^{93}$ A. Delin, O. Eriksson, R. Ahuja, B. Johansson, M. S. S. Brooks, T. Gasche, S. Auluck, and J. M. Wills, Phys. Rev. B 54, 1673 (1996).

${ }^{94}$ P. Prieto, A. Fernández, L. Soriano, F. Yubero, E. Elizalde, A. R. González-Elipe, and J. M. Sanz, Phys. Rev. B 51, 17984 (1995),

${ }^{95}$ P. Prieto, Ph.D. Thesis, Universidad Autónoma de Madrid, (1992)

${ }^{96}$ L. Porte, Solid State Commun. 50, 303 (1984).

${ }^{97}$ J. Lindström, L. I. Johansson, A. Callenas, D. S. L. Law, and A. N. Christensen, Phys. Rev. B 35, 7891 (1987).

${ }^{98}$ J. S. Foord, P. J. Goddard, and R. M. Lambert, Surf. Sci. 94, 339 (1980).

JAP 104907-14 
${ }^{99}$ H. Wiame, P. Grange, M.-A. Centeno, S. Picard, P. Bastians, and P. Grange, J. Eur. Ceram. Soc. 18, 1293 (1998).

${ }^{100}$ I. Milošev, H.-H. Strehblow, and B. Navinšek, Thin Solid Films 303, 246 (1997).

${ }^{101}$ P. Prieto, L. Galán, and J. M. Sanz, Phys. Rev. B 47, 1613 (1993)

${ }^{102}$ W. E. Swartz, Jr, and D. M. Hercules, Anal. Chem. 43, 1774 (1971).

${ }^{103}$ W. E. Swartz, Jr., K. J. Wynne, and D. M. Hercules, Anal. Chem. 43 1884 (1971).

${ }^{104}$ C. Morant, J. M. Sanz, and L. Galan, Phys. Rev. B 45, 1391 (1992). ${ }^{105}$ T. Goto, H. Ishigaki, and Y. Ito, Mater. Sci. Eng., A 371, 353 (2004). ${ }^{106}$ C. Ernsberger, J. Nickerson, A. E. Miller, and J. Moulder, J. Vac. Sci. Technol. A 3, 2415 (1985)

${ }^{107}$ K. S. Robinson and P. M. A. Sherwood, Surf. Interface Anal. 6, 261 (1984).
${ }^{108}$ J. Vasile, A. B. Emerson, and F. A. Baiocchi, J. Vac. Sci. Technol. A 8, 99 (1990).

${ }^{109}$ M. A. Signore, A. Rizzo, L. Mirenghi, M. A. Tagliente, and A. Cappello, Thin Solid Films 515, 6798 (2007)

${ }^{110}$ H. M. Benia, M. Guemmaz, G. Scmerber, A. Mosser, and J. C. Parlebas, Appl. Surf. Sci. 200, 231 (2002).

${ }^{111}$ C.-P. Liu and H.-G. Yang, Thin Solid Films 444, $111(2003)$

${ }^{112}$ J. M. Chappe, N. Martin, J. F. Pierson, G. Terwagne, J. Lintymer, J. Gavoille, and J. Takadoum, Appl. Surf. Sci. 225, 29 (2004)

${ }^{113}$ D. Pilloud, A. S. Dehlinger, J. F. Pierson, A. Roman, and L. Pichon, Surf. Coat. Technol. 174-175, 338 (2003).

${ }^{114}$ H. B. Bhuvaneswari, I. Nithiya Priya, R. Chandramani, V. Rajagopal Reddy, and G. Mohan Rao, Cryst. Res. Technol. 38, 1047 (2003).

JAP 104907-15 